\title{
Aerosol optical properties in a rural environment near the mega-city Guangzhou, China: implications for regional air pollution, radiative forcing and remote sensing
}

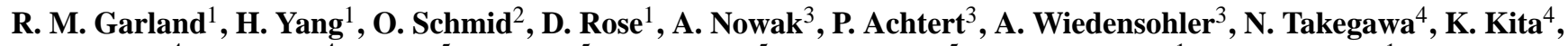 \\ Y. Miyazaki ${ }^{4}$, Y. Kondo ${ }^{4}$, M. Hu ${ }^{5}$, M. Shao ${ }^{5}$, L. M. Zeng ${ }^{5}$, Y. H. Zhang ${ }^{5}$, M. O. Andreae ${ }^{1}$, and U. Pöschl ${ }^{1}$ \\ ${ }^{1}$ Max Planck Institute for Chemistry, Biogeochemistry Department, Mainz, Germany \\ ${ }^{2}$ Helmholtz Ctr. Munich, German Research Ctr. for Environmental Health, Inst. for Inhalation Biology, Neuherberg, Germany \\ ${ }^{3}$ Leibniz Institute for Tropospheric Research, Leipzig, Germany \\ ${ }^{4}$ RCAST, University of Tokyo, Tokyo, Japan \\ ${ }^{5}$ State Key Joint Laboratory of Environmental Simulation and Pollution Control, College of Environmental Sciences and \\ Engineering, Peking University, Beijing, China
}

Received: 6 February 2008 - Published in Atmos. Chem. Phys. Discuss.: 9 April 2008

Revised: 24 July 2008 - Accepted: 2 August 2008 - Published: 3 September 2008

\begin{abstract}
The scattering and absorption of solar radiation by atmospheric aerosols is a key element of the Earth's radiative energy balance and climate. The optical properties of aerosol particles are, however, highly variable and not well characterized, especially near newly emerging mega-cities. In this study, aerosol optical properties were measured at a rural site approximately $60 \mathrm{~km}$ northwest of the mega-city Guangzhou in southeast China. The measurements were part of the PRIDE-PRD2006 intensive campaign, covering the period of 1-30 July 2006. Scattering and absorption coefficients of dry aerosol particles with diameters up to $10 \mu \mathrm{m}$ $\left(\mathrm{PM}_{10}\right)$ were determined with a three-wavelength integrating nephelometer and with a photoacoustic spectrometer, respectively.

Averaged over the measurement campaign (arithmetic mean \pm standard deviation), the total scattering coefficients were $200 \pm 133 \mathrm{Mm}^{-1}(450 \mathrm{~nm}), 151 \pm 103 \mathrm{Mm}^{-1}(550 \mathrm{~nm})$ and $104 \pm 72 \mathrm{Mm}^{-1}(700 \mathrm{~nm})$ and the absorption coefficient was $34.3 \pm 26.5 \mathrm{Mm}^{-1}(532 \mathrm{~nm})$. The average Ångström exponent was $1.46 \pm 0.21(450 \mathrm{~nm} / 700 \mathrm{~nm})$ and the average single scattering albedo was $0.82 \pm 0.07(532 \mathrm{~nm})$ with minimum values as low as 0.5 . The low single scattering albedo values indicate a high abundance, as well as strong sources, of light absorbing carbon (LAC). The ratio of LAC to CO concentration was highly variable throughout the campaign, indicating a complex mix of different combustion sources. The scattering and absorption coefficients, as well as the
\end{abstract}

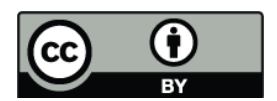

Correspondence to: R. M. Garland (garland@ mpch-mainz.mpg.de)
Ångström exponent and single scattering albedo, exhibited pronounced diurnal cycles, which can be attributed to boundary layer mixing effects and enhanced nighttime emissions of LAC (diesel soot from regulated truck traffic). The daytime average mid-visible single scattering albedo of 0.87 appears to be more suitable for climate modeling purposes than the 24-h average of 0.82 , as the latter value is strongly influenced by fresh emissions into a shallow nocturnal boundary layer. In spite of high photochemical activity during daytime, we found no evidence for strong local production of secondary aerosol mass.

The average mass scattering efficiencies with respect to $\mathrm{PM}_{10}$ and $\mathrm{PM}_{1}$ concentrations derived from particle size distribution measurements were $2.8 \mathrm{~m}^{2} \mathrm{~g}^{-1}$ and $4.1 \mathrm{~m}^{2} \mathrm{~g}^{-1}$, respectively. The Ångström exponent exhibited a wavelength dependence (curvature) that was related to the ratio of fine and coarse particle mass $\left(\mathrm{PM}_{1} / \mathrm{PM}_{10}\right)$ as well as the surface mode diameter of the fine particle fraction. The results demonstrate consistency between in situ measurements and a remote sensing formalism with regard to the fine particle fraction and volume mode diameter, but there are also systematic deviations for the larger mode diameters. Thus we suggest that more data sets from in situ measurements of aerosol optical parameters and particle size distributions should be used to evaluate formalisms applied in aerosol remote sensing. Moreover, we observed a negative correlation between single scattering albedo and backscatter fraction, and we found that it affects the impact that these parameters have on aerosol radiative forcing efficiency and should be considered in model studies of the PRD and similarly polluted mega-city regions. 


\section{Introduction}

Mega-cities, large urban areas with populations of greater than 10 million people, emerged in the twentieth century. In 1950 there were only two (New York and Tokyo) and in 2005 there were twenty (UN, 2005). While there are many benefits to this increased urbanization (i.e., more access to education and economic advantages), this high growth rate also presents many environmental problems, including the degradation of air quality. The environmental impacts of air pollution in large cities are not just restricted to their borders, but rather the pollutants are transported and can then have regional and global impacts (Lawrence et al., 2007).

Aerosol particles are a major component of urban air pollution and can have negative effects on human health, can impact cloud formation and lifetime, and can influence heterogeneous reactions (Seinfeld and Pandis, 1998; FinlaysonPitts and Pitts, 1999; Pöschl, 2005). Moreover, they scatter and absorb incoming solar radiation impacting visibility as well as the radiative balance of the atmosphere. For example, the increasing concentrations of anthropogenic aerosol particles in China since the 1950's have been linked to decreasing amounts of sunshine duration and changing summertime maximum temperatures (Kaiser and Qian, 2002).

The Pearl River Delta (PRD) region in southeastern China is a rapidly growing area, both economically and in population. This area contains many cities, including Hong Kong, Guangzhou and Shenzhen. The PRD region is named after the Pearl River that, together with its tributaries, runs through this region. The river delta is bordered by the Nan Ling Mountains from the northwest to the southwest and the river empties into the South China Sea in between Hong Kong and Macau. Guangdong province, which contains both Guangzhou and Shenzhen, has a population of approximately 92 million people and the third largest Gross Domestic Product in China (NBS, 2007). By 2015, Guangzhou itself is projected to have more than 10 million inhabitants, and will thus officially be considered a mega-city (UN, 2005). As the industry and population in the PRD region increases, so do the environmental impacts of this growth. Nearly half of the urban river water bodies in Guangdong province are seriously polluted; leading to clean water shortages in an area with large natural water resources (Ouyang et al., 2006). The increase in industry and population also impacts the area's air quality. For a detailed description of the air pollution and meteorology of the entire PRD region, see Chan and Yao (2008).

The PRD region is often plagued with high aerosol concentrations that lead to not only low visibility, $\sim 50 \%$ of days in 2006 had visibility $<1 \mathrm{~km}$ in Shenzhen, but can also impact the radiative balance of the region (Wu et al., 2005; Chan and Yao, 2008). Previous studies in PRD have measured average aerosol mass concentrations for $\mathrm{PM}_{10}$ (particulate matter with aerodynamic particle diameter $\leq 10 \mu \mathrm{m}$ ) of 70-234 $\mu \mathrm{g} / \mathrm{m}^{3}$ (Wei et al., 1999; Cao et al., 2003; Cao et al., 2004; Chen et al., 2007), with average concentrations gener- ally above $200 \mu \mathrm{g} / \mathrm{m}^{3}$ in Guangzhou in the winter (Cao et al., $2003)$ and around $100 \mu \mathrm{g} / \mathrm{m}^{3}\left(\mathrm{PM}_{2.5}\right.$; particulate matter with aerodynamic particle diameter $\leq 2.5 \mu \mathrm{m}$ ) in the fall (Andreae et al., 2008), and with a large percentage of the particulate mass $(>58 \%)$ in the $\mathrm{PM}_{2.5}$ fraction.

Andreae et al. (2008) measured the aerosol optical properties in urban Guangzhou in October 2004 as part of the "Program of Regional Integrated Experiments of Air Quality over the Pearl River Delta" (PRIDE-PRD) campaign 2004. During that campaign the air masses generally came from the northeast, bringing continental pollution into the PRD region (Cheng et al., 2006b; Zhang et al., 2008). In order to complement these autumn measurements of continental pollution influencing the PRD region, this study characterizes the properties of aerosols and regional pollution from sources in the Pearl River Delta itself. During the summer, while the $\mathrm{PM}_{10}$ concentration is generally lowest, the low inland wind speeds can lead to an accumulation of regional pollution, even in rural areas (Chan and Yao, 2008). Previous studies in Hong Kong have indicated that up to $60 \%$ of $\mathrm{PM}_{10}$ mass was due to regional sources (Chan and Yao, 2008 and references therein). Additionally, it has been found that Guangzhou is a major source of regional pollution, accounting for up to $60 \%$ of particulate levels in areas downwind (Hagler et al., 2006). During the PRIDE-PRD2006 campaign in July 2006, we measured the aerosol optical properties in a rural site $\sim 60 \mathrm{~km} \mathrm{NW}$ of the city of Guangzhou. This site was well situated to measure the outflow of the PRD region due to the monsoon circulation during this period. Because of this meteorology, the sampled air masses came mainly from the south/southeast, off the South China Sea and passed over the PRD region before arriving at the measurement site.

\section{Methods}

\subsection{Measurement location and supporting data}

The measurements were performed in Backgarden $\left(23.548056^{\circ} \mathrm{N}, 113.066389^{\circ} \mathrm{E}\right)$, a small village in a rural farming environment on the outskirts of the densely populated center of the PRD (Fig. 1), during the PRIDEPRD2006 campaign (1-30 July 2006), the summertime complementary study to PRIDE-PRD2004 (Zhang et al., 2008). There were two main measurement sites for this campaign; the Backgarden site was chosen as the rural site, with minor local sources, and there was an urban site in downtown Guangzhou. At each of these sites a wide range of aerosol, gas phase and meteorological parameters were measured to characterize local and regional air pollution (Hua et al., 2008; Liu et al., 2008)

As seen in Fig. 1, the Backgarden site was situated on the edge of the highly populated PRD region, though the area itself was mostly a farming area. Due to monsoon circulation, the air masses throughout this campaign came mainly from 
the south/southeast, making this site a rural receptor site for the regional pollution resulting from the outflow of the city cluster around Guangzhou. A two-story hotel located next to a reservoir was used exclusively to house the measurement campaign, with most of the instruments placed in air conditioned rooms on the top floor and sample inlets mounted on the rooftop.

Local meteorological parameters were measured on the roof, next to the sample inlets (Weather Transmitter WXT510, Vaisala, Finland; operated by University of Tokyo). The average meteorological values (arithmetic mean \pm standard deviation) for the campaign were: $28.9 \pm 3.2^{\circ} \mathrm{C}$ ambient temperature, $78.0 \pm 13.7 \%$ ambient relative humidity (RH), $997 \pm 4 \mathrm{hPa}$ ambient pressure, $1.8 \pm 1.2 \mathrm{~m} \mathrm{~s}^{-1}$ local wind speed, $143 \pm 53^{\circ}$ local wind direction.

The main aerosol inlet used in this study was equipped with a Rupprecht and Patashnick $\mathrm{PM}_{10}$ inlet that was optimized for isokinetic flow conditions with a cyclone (flow rate $16.7 \mathrm{~L} \mathrm{~min}^{-1}$ ). The sample flow passed through stainless steel tubing $(1.9 \mathrm{~cm}, 5.1 \mathrm{~m})$ and a diffusion dryer with silica gel/molecular sieve cartridges (alternating regeneration with dry pressurized air, regeneration cycles 15-50 min, average $\mathrm{RH}=33 \pm 7 \%$ ). After drying, the sample flow was split into separate lines. One line was for the aerosol optical instruments $(0.94 \mathrm{~cm}$ stainless steel, $\sim 5 \mathrm{~m}$ and flow rate $\left.6 \mathrm{~L} \mathrm{~min}^{-1}\right)$. Another line was for the aerosol sizing instruments (particle diameter $\leq 10 \mu \mathrm{m}$ ), namely a Twin Differential Mobility Particle Sizer (TDMPS, IfT) and an Aerodynamic Particle Sizer (APS, TSI 3321). The inlet, dryer and size distribution measurements were operated by the Leibniz Institute for Tropospheric Research (IfT). The particle number concentration and average modal diameter results presented below are 10-min averages; the mass concentrations were calculated assuming an average particle density of $1.7 \mathrm{~g} \mathrm{~cm}^{-3}$. Measurements of nitrogen oxides $\left(\mathrm{NO}_{\mathrm{x}}=\mathrm{NO}+\mathrm{NO}_{2}\right)$, total reactive nitrogen $\left(\mathrm{NO}_{\mathrm{y}}\right)$ and ozone $\left(\mathrm{O}_{3}\right)$ were performed using a separate inlet and sampling line, which will be described in detail elsewhere (TECO 42CTL; operated by University of Tokyo). The $\mathrm{NO}_{2}$ data were required for correction of the photoacoustic spectrometer data. The $\mathrm{CO}$ concentration was measured using a nondispersive infrared absorption instrument (Model 48, Thermo Environmental Instruments, USA; operated by University of Tokyo). The instrument was coupled with a Nafion dryer (Perma-Pure Inc. USA) to reduce the interference from water vapor (Takegawa et al., 2006).

\subsection{Optical instrumentation and extensive properties}

Total aerosol particle scattering coefficients $\left(\sigma_{s, \lambda}\right)$ and hemispheric backscattering coefficients $\left(\sigma_{b s, \lambda}\right)$ at three different wavelengths $(\lambda=450 \mathrm{~nm}, 550 \mathrm{~nm}$, and $700 \mathrm{~nm})$ were measured with an integrating nephelometer (Model 3563, TSI). The nephelometer was operated at $5 \mathrm{~L} \mathrm{~min}^{-1}$ with a two minute averaging time. An auto zero, where particle-free
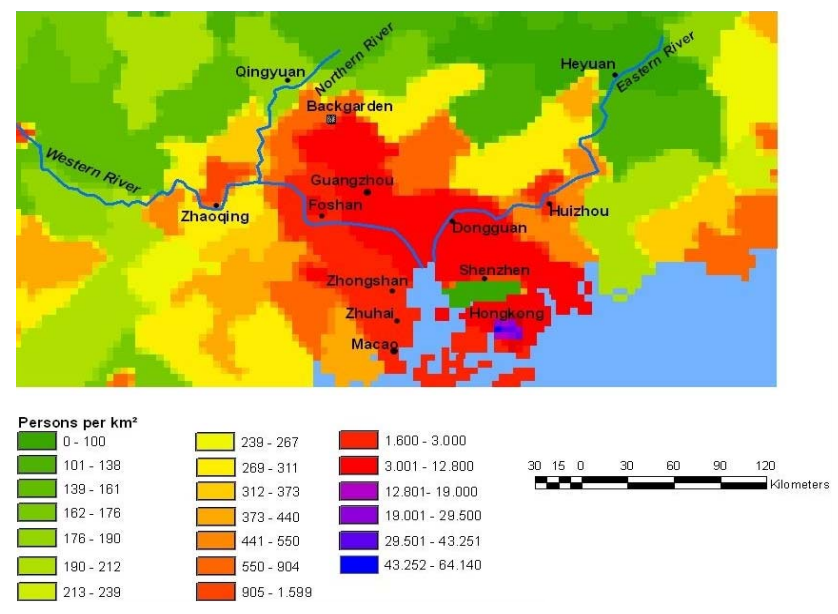

Fig. 1. Map of southeastern China colored by population density $\left(\mathrm{km}^{-2}\right)$. The measurement location (Backgarden) and major cities in the area are labeled. Data source: Socioeconomic data and application center of the Columbia University.

air was sampled, was performed every $2 \mathrm{~h}$. The nephelometer contains two temperature sensors, one relative humidity sensor and a pressure sensor. These sensors are used to report room temperature and the conditions in the measurement chamber. The relative humidity of the sample flow was $31.5 \pm 4.8 \%$. Within this range, no systematic correlation between sample flow RH and measured optical parameters was observed, indicating that the variations of drying efficiency had no significant influence on the optical measurement results. For the campaign, the average sampling pressure and temperature as measured inside the nephelometer were $996 \pm 4 \mathrm{hPa}$ and $23 \pm 1^{\circ} \mathrm{C}$, respectively. The campaign average for the nephelometer lamp power was $50.6 \pm 1.1 \mathrm{~W}$.

The nephelometer was calibrated with filtered air and $\mathrm{CO}_{2}$ gas as described in the instrument's manual. The calibration was performed at the beginning, middle and end of the campaign. On average, the calibration constants were within $\pm 2 \%$ of each other. The measurement data were corrected for truncation errors and a nonlambertian light source using the Ångström exponents that were calculated as described in Sect. 2.3.1 below (Anderson et al., 1996; Anderson and Ogren, 1998). On average, the corrected values were within $15 \%$ of the measured values for the whole campaign.

The effective limit of detection (ELOD) under the current operating condition was determined for the nephelometer signals using their respective zero signals collected during the instrument's auto zeroing time. The instrument's software automatically subtracted these zero values from the measured signals and the ELOD was three times the standard deviation of the zero signals. The campaign average ELOD values can be seen in Table 1. Any value below the ELOD was discarded. In the end, $0.1 \%$ of the nephelometer data were discarded due to ELOD reasons. The measurement 
Table 1. Average optical parameters (arithmetic mean \pm standard deviation) for the complete campaign, the campaign excluding the "intense smoky period", and the "intense smoky period" (23-25 July) as well as effective limits of detection (ELOD) for the measured extensive optical parameters. Listed are also the average number concentrations of particles with $D_{p} \geq 100 \mathrm{~nm}\left(N_{100}\right)$, the mass concentrations of particles with $D_{p} \leq 1 \mu \mathrm{m}\left(\mathrm{PM}_{1}\right)$ and $D_{p} \leq 10 \mu \mathrm{m}\left(\mathrm{PM}_{10}\right)$, and the effective mode diameters from mono-modal lognormal fits to the measured submicron size-distributions of particle number $\left(D_{p, n}\right)$, surface area $\left(D_{p, s}\right)$ and volume $\left(D_{p, v}\right)$.

\begin{tabular}{llllr}
\hline Parameter & All campaign & $\begin{array}{l}\text { Campaign without intense } \\
\text { smoky period }\end{array}$ & Intense smoky period & ELOD \\
\hline$\sigma_{s, 450}\left(\mathrm{Mm}^{-1}\right)$ & $266 \pm 271$ & $200 \pm 133$ & $791 \pm 454$ & 15.6 \\
$\sigma_{b s, 450}\left(\mathrm{Mm}^{-1}\right)$ & $28.4 \pm 25.9$ & $22.4 \pm 13.7$ & $76.4 \pm 43.7$ & 1.7 \\
$\sigma_{s, 550}\left(\mathrm{Mm}^{-1}\right)$ & $200 \pm 208$ & $151 \pm 103$ & $597 \pm 358$ & 12.3 \\
$\sigma_{b s, 550}\left(\mathrm{Mm}^{-1}\right)$ & $23.0 \pm 21.6$ & $18.0 \pm 11.2$ & $63.0 \pm 37.4$ & 1.3 \\
$\sigma_{s, 700}\left(\mathrm{Mm}^{-1}\right)$ & $137 \pm 143$ & $104 \pm 72$ & $401 \pm 252$ & 8.4 \\
$\sigma_{b s, 700}\left(\mathrm{Mm}^{-1}\right)$ & $19.9 \pm 19.4$ & $15.4 \pm 9.7$ & $55.8 \pm 34.4$ & 1.2 \\
$\sigma_{a, 532}\left(\mathrm{Mm}^{-1}\right)$ & $42.5 \pm 56.5$ & $34.3 \pm 26.5$ & $106 \pm 133$ & 5.4 \\
$a_{s}(550 / 700)$ & $1.57 \pm 0.21$ & $1.51 \pm 0.22$ & $1.63 \pm 0.23$ & - \\
$a_{s}(450 / 700)$ & $1.51 \pm 0.20$ & $1.46 \pm 0.21$ & $1.50 \pm 0.24$ & - \\
$a_{s}(450 / 550)$ & $1.44 \pm 0.20$ & $1.38 \pm 0.22$ & $1.34 \pm 0.25$ & - \\
$b_{450}$ & $0.11 \pm 0.014$ & $0.116 \pm 0.013$ & $0.097 \pm 0.008$ & - \\
$b_{550}$ & $0.12 \pm 0.016$ & $0.124 \pm 0.015$ & $0.106 \pm 0.011$ & - \\
$b_{700}$ & $0.15 \pm 0.017$ & $0.154 \pm 0.017$ & $0.141 \pm 0.014$ & - \\
$\omega_{532}$ & $0.83 \pm 0.07$ & $0.82 \pm 0.07$ & $0.88 \pm 0.06$ & - \\
$N_{100}(\mathrm{~cm}-3)$ & $5200 \pm 3550$ & $4530 \pm 2780$ & $9110 \pm 4770$ & - \\
$\mathrm{PM}_{1}(\mu \mathrm{g} \mathrm{m}-3)$ & $60 \pm 57$ & $45 \pm 26$ & $135 \pm 96$ & - \\
$\left.\mathrm{PM}_{10}(\mu \mathrm{g} \mathrm{m})^{-3}\right)$ & $85 \pm 66$ & $69 \pm 37$ & $166 \pm 108$ & - \\
$D_{p, n}(\mathrm{~nm})$ & $69 \pm 27$ & $63 \pm 20$ & $112 \pm 27$ & - \\
$D_{p, s}(\mathrm{~nm})$ & $192 \pm 58$ & $180 \pm 50$ & $377 \pm 52$ & - \\
$D_{p, v}(\mathrm{~nm})$ & $357 \pm 259$ & $353 \pm 277$ & & - \\
\hline & & & & - \\
\hline
\end{tabular}

uncertainty of the nephelometer was not determined during the field campaign (Anderson et al., 1996). However, the instrument was run with an identical set-up in Beijing directly after the PRIDE-PRD2006 campaign (Garland et al., submitted). The nephelometer performed similarly in both campaigns. Cheng et al. $\left(2008^{1}\right)$ have compared the Beijing nephelometer measurements to a Mie model and found them to agree within $\pm 8 \%$. Thus we assume that the uncertainty of the nephelometer data is less than $10 \%$ for both campaigns.

The aerosol particle absorption coefficient at $532 \mathrm{~nm}$ $\left(\sigma_{a}, 532\right)$ was determined with a photoacoustic spectrometer (PAS; Desert Research Institute), which provides highly sensitive absorption measurements without interference by scattering signals. The instrument has been described elsewhere in detail (Arnott et al., 1999). Briefly, a flow of aerosol $\left(0.8 \mathrm{~L} \mathrm{~min}^{-1}\right)$ enters into an acoustic resonator and is illuminated by laser light (Nd:YAG, $\lambda=532 \mathrm{~nm}, 50 \mathrm{~mW}$ ) which is modulated at the acoustic resonator frequency $(1510 \mathrm{~Hz})$. The light energy absorbed by the aerosol particles is re-

\footnotetext{
${ }^{1}$ Cheng, Y. F., Berghof, M., Garland, R. M., Wiedensohler, A., Wehner, B., Achtert, P., Nowak, A., Su, H., Pöschl, U., Zhang, Y. H., Zhu, T. and Zeng, L. M.: Influence of mixing state on aerosol light absorption during air mass aging processing at a polluted regional site near Beijing, J. Geophys. Res.-Atmos., submitted, 2008.
}

released as heat, producing a pressure wave that is detected by a microphone. The instrument was operated with an integration time of $\sim 10 \mathrm{~s}$ and calibrated with gaseous $\mathrm{NO}_{2}$ ( 1000 ppm) (Arnott et al., 2000; Schmid et al., 2006). The data were averaged for two minutes to match the time scale of the nephelometer. The instrument noise was measured on the same time scale as the signal. The overall accuracy of the PAS calibration in this study was within $10 \%$, thus the overall accuracy of the measured PAS absorption coefficients are also $\pm 10 \%$ (Schnaiter, 2005). A zero measurement of filtered (Acro 50 Filters, Gelman), particle-free air was performed every $10-15 \mathrm{~min}$ for a period of $\sim 1 \mathrm{~min}$. The absorption coefficient that was measured during the zeroing periods was set as $0 \mathrm{Mm}^{-1}$, thereby accounting for absorption by $\mathrm{NO}_{2}$ (and any other potential gaseous absorbers). If, however, the ambient $\mathrm{NO}_{2}$ concentration changed during the $10-15$ min sampling period following the zeroing period, the recorded aerosol particle absorption coefficients could be influenced by the changing background signal from $\mathrm{NO}_{2}$. Thus, the photoacoustic measurement data have been corrected for ambient $\mathrm{NO}_{2}$ concentration as described in Schmid et al. (2006), except for the periods of 1-5 July and 27-30 July, when ambient $\mathrm{NO}_{2}$ measurement data were not available. A plot of corrected PAS data vs. uncorrected PAS data 
gave a linear least squares fit equation of $y=0.998 x+0.0755$ with $R^{2}=0.9995, n=11,251$; the relative deviation between corrected and uncorrected data was on average only $1.7 \%$. For $97.6 \%$ of the data points this deviation was less than $10 \%$, and for only seven out of 11251 data points did the deviation exceed $50 \%$. Hence, the corrections due to varying $\mathrm{NO}_{2}$ levels were generally small, and it is safe to assume that the uncorrected data for the periods of 1-5 July and 27-30 July are not affected by any substantial errors.

In order to filter out data that are impacted by noise, all high noise events (noise $\geq 30 \mathrm{Mm}^{-1}$, e.g., due to strong external vibrations) and their corresponding data points were excluded. The measured signal and instrument noise $(N)$ were averaged over two minutes. The ELOD was defined as three times the average noise $\left(\operatorname{ELOD}_{\mathrm{PAS}}=3 \sum_{i=1}^{n} N_{i} n^{-3 / 2}\right.$; $n=$ number of points; W. P. Arnott, personal communication). Any absorption coefficient data that were smaller than the ELOD for their respective time period were discarded (3\% of data). The campaign average of the ELOD for the PAS can be seen in Table 1.

\subsection{Intensive properties}

\subsection{1 Ångström exponent}

In analogy to aerosol optical depth or extinction, the wavelength dependence of aerosol scattering coefficients can be approximated by a power law (Ångström, 1929),

$\sigma_{\mathrm{s}, \lambda}=\sigma_{\mathrm{s}, \lambda r}\left(\lambda / \lambda_{r}\right)^{-\stackrel{\circledR}{a}_{s}}$,

where $\sigma_{s, \lambda r}$ is the scattering coefficient at a given reference wavelength $\lambda_{r}$, and $\stackrel{\circ}{a}_{s}$ is the dimensionless Angström exponent. The Ångström exponent corresponds to the slope of a double-logarithmic plot of $\sigma_{s}$ vs. $\lambda$ as seen in Fig. 2 and is calculated according to Eq. (2).

$\stackrel{\circ}{a}_{s}\left(\lambda_{1} / \lambda_{2}\right)=-\frac{\log \left(\sigma_{\mathrm{s}, \lambda_{1}} / \sigma_{\mathrm{s}, \lambda_{2}}\right)}{\log \left(\lambda_{1} / \lambda_{2}\right)}$

If this plot is linear, as shown in Fig. 2a, then $\stackrel{\circ}{a}_{s}$ is independent of $\lambda$. However, $\stackrel{\circ}{a}_{s}$ can exhibit a dependency on $\lambda$, as seen in Fig. 2b. This wavelength dependence is characterized by the curvature seen in Fig. $2 \mathrm{~b}$ and quantified by the second derivative of the double-logarithmic plot of $\sigma_{s}$ vs. $\lambda$ (i.e., the first derivative of the Ångström exponent) as $\stackrel{\circ}{a}_{s}^{\prime}$. The second derivative for the wavelength interval centered around $550 \mathrm{~nm}, \stackrel{\circ}{a}_{s}^{\prime}(550)$, has been approximated by Eq. (3) (Li et al., 1993; Eck et al., 1999).

$\stackrel{\circ}{a}_{s}^{\prime}(550)=\left(\frac{2}{\log (450 / 700)}\right)\left(\stackrel{\circ}{a}_{S}(450 / 550)-\stackrel{\circ}{a}_{S}(550 / 700)\right)$

In this study, the measured scattering coefficients have been used to calculate Ångström exponent values $\left(\stackrel{\circ}{a}_{s}\left(\lambda_{1} / \lambda_{2}\right)\right)$ for the wavelength pairs of $450 / 550 \mathrm{~nm}, 550 / 700 \mathrm{~nm}$, and
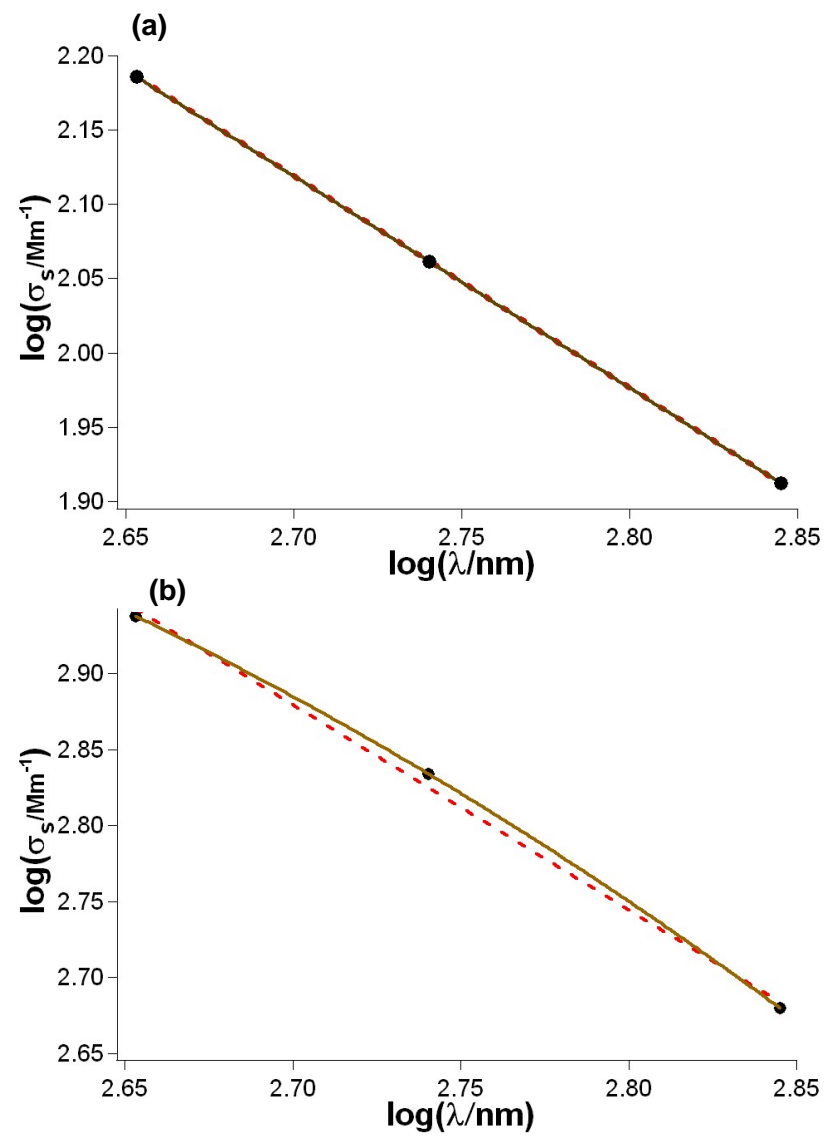

Fig. 2. Double-logarithmic plot of scattering coefficient $\left(\sigma_{s}\right.$, ) versus wavelength ( $\lambda$ ) for (a) 18 July 2006 and (b) 25 July 2006. The dotted line is a linear fit. The negative slope of this fit is the Angström exponent $\stackrel{\circ}{a}_{S}$ ). The solid line is a second order polynomial fit (King and Byrne 1976).

$450 / 700 \mathrm{~nm}$. The curvature was quantified using these $\stackrel{\circ}{a}_{s}$ values to calculate the $\stackrel{\circ}{s}_{s}^{\prime}$.

The second derivative values $\left(\stackrel{(}{ }^{\prime}\right)$ reported in the literature generally use the Ångström exponent calculated from extinction coefficients $\stackrel{\circ}{a}_{e}$ ), while in the current study, the scattering coefficients were used as indicated by the " $s$ " subscript. When comparing $\stackrel{\circ}{a}_{s}^{\prime}$ and $\stackrel{\circ}{a}_{e}^{\prime}$, it is possible that differences might arise from a potential wavelength dependence of absorption. This was investigated by converting $\sigma_{s}$ into extinction coefficients $\left(\sigma_{e}=\sigma_{s}+\sigma_{a}\right)$ at all three wavelengths $(450 \mathrm{~nm}, 550 \mathrm{~nm}$ and $700 \mathrm{~nm})$ using $\sigma_{a, 532}$ and assuming a $\lambda^{-1}$ and $\lambda^{-2}$ wavelength dependence of absorption (Bergstrom et al., 2002). The $\stackrel{\circ}{a}_{e}$ and $\stackrel{\circ}{a}_{e}^{\prime}$ values were then calculated in analogy to Eqs. (2) and (3).

\subsubsection{Backscattering fraction and single scattering albedo}

The angular corrected backscattering coefficient from the nephelometer is the scattered light intensity in the backward hemisphere of the particle $\left(90-180^{\circ}\right)$ (Anderson and Ogren, 


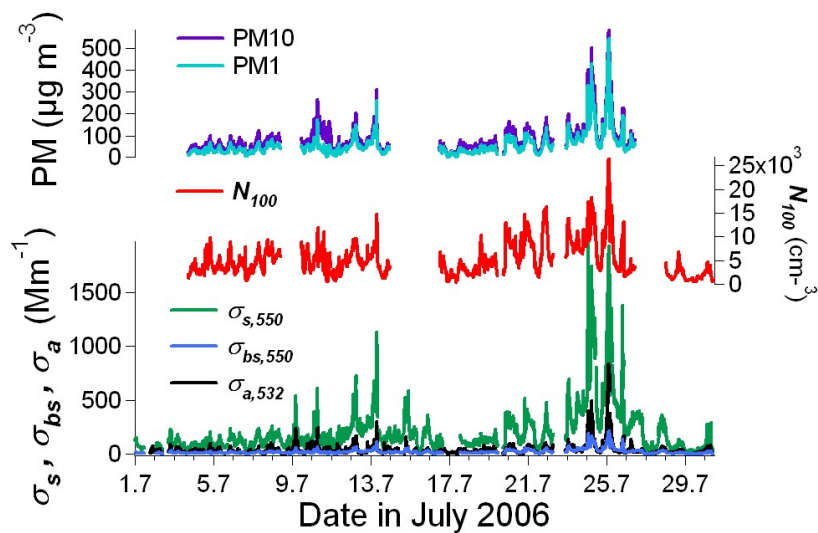

Fig. 3. Time series for the extensive optical properties measured in the green spectral range: scattering, backscattering, and absorption coefficients $\left(\sigma_{s, 550}, \sigma_{b s, 550}, \sigma_{a, 532}\right)$, for the aerosol particle number concentration in the diameter range of $100 \mathrm{~nm}$ to $10 \mu \mathrm{m}$ $\left(N_{100}\right)$ and the mass concentrations of particles $D_{p} \leq 1 \mu \mathrm{m}\left(\mathrm{PM}_{1}\right)$ and $D_{p} \leq 10 \mu \mathrm{m}\left(\mathrm{PM}_{10}\right)$ inferred from size distribution measurements plotted against the date in July 2006.

1998). The hemispheric backscattering fraction, $b_{\lambda}$, is the ratio of this backscattering coefficient over total scattering coefficient at a given wavelengths $(\lambda=450,550$, and $700 \mathrm{~nm})$.

$b_{\lambda}=\frac{\sigma_{b s, \lambda}}{\sigma_{s, \lambda}}$

The single scattering albedo, $\omega_{\lambda}$, is the ratio of the scattering coefficient over the extinction coefficient at a given wavelength. Here $\omega$ has been calculated at $\lambda=532 \mathrm{~nm}$ using Eq. (5).

$\omega_{532}=\frac{\sigma_{s, 532}}{\sigma_{s, 532}+\sigma_{a, 532}}$

The $\sigma_{s, 532}$ was not measured directly by the nephelometer, but rather was calculated using Eq. (2) with the inputs, $\stackrel{\circ}{a}_{s}=\stackrel{\circ}{a}_{s}$ (550/700) $\sigma_{s, \lambda 1}=\sigma_{s, 550}$ and with $\lambda_{1}=550 \mathrm{~nm}$ and $\lambda_{2}=532 \mathrm{~nm}$. Test calculations using $\stackrel{\circ}{a}_{s}$ (450/700) and $\stackrel{\circ}{a}_{s}$ (450/550) instead of $\stackrel{\circ}{a}_{s}(550 / 700)$ gave only slightly different results (relative deviations in $\sigma_{s, 532}<1 \%$ ). By propagating the uncertainty in $\sigma_{s}$ and $\sigma_{a}$ reported above using a Monte Carlo simulation, the uncertainty in $\omega_{532}$ for this campaign is $\pm 2 \%$.

\section{Results and discussion}

3.1 Overview of optical measurement results (time series and statistical distribution)

\subsubsection{Extensive properties}

Figure 3 shows the time series of the aerosol particle total scattering, backscattering and absorption coefficients for the green spectral range $\left(\sigma_{s}, 550, \sigma_{b s}, 550, \sigma_{a}, 532\right)$ throughout the measurement campaign. The scattering and backscattering coefficients at $\lambda=450 \mathrm{~nm}$ and $700 \mathrm{~nm}\left(\sigma_{s}, 450, \sigma_{b s}, 450, \sigma_{s}, 700\right.$, $\left.\sigma_{b s}, 700\right)$ followed essentially the same trends as those for $550 \mathrm{~nm}$. They generally tracked well with the particle number concentration in the diameter range of $100 \mathrm{~nm}$ to $10 \mu \mathrm{m}$ $\left(N_{100}\right)$ as well as with the mass concentrations of particles $D_{p} \leq 1 \mu \mathrm{m}\left(\mathrm{PM}_{1}\right)$ and $D_{p} \leq 10 \mu \mathrm{m}\left(\mathrm{PM}_{10}\right)$. A more detailed discussion of relationships between particle number concentration, mass concentration and size with optical properties can be found in Sect. 3.4.

Together with particle number and mass concentration, the extensive aerosol optical properties exhibited very high variability ranging from the instrument detection limits on rainy days such as 17 July to extremely high values during a heavy pollution episode (23-25 July) characterized by intense local biomass burning. During this period, the source of the pollution was evident and unique: the burning of plant waste by local farmers was visible in the vicinity surrounding the measurement site, and it was the only time that such intense local biomass burning and pollution occurred during the campaign. Thus, the data from the most heavily polluted time period of the burning event (23 July, 00:00-25 July 2006, 23:59) were excluded from the calculation of campaign averages, all data analyses in this paper and will be treated separately, unless stated otherwise. This period will be referred to as the "intense smoky period", and the properties of the local biomass burning aerosol will be compared to the average optical properties, which are more impacted by regional sources as discussed below.

The extensive properties measured during this "intense smoky period" contained many of the highest values of the campaign and were up to four times larger than during the rest of the campaign (average relative increase: $+300 \%$ for $\sigma_{s},+250 \%$ for $\sigma_{b s},+200 \%$ for $\sigma_{a}$ ). The differences between the campaign averages with and without 23-25 July 2006 are shown in Table 1, including the measured aerosol optical properties, the particle number and mass concentrations inferred form particle size distribution measurements as well as the effective mode diameters from mono-modal lognormal fits to the measured submicron size-distributions of particle number $\left(D_{p, n}\right)$, surface area $\left(D_{p, s}\right)$ and volume $\left(D_{p, v}\right)$. For example, the relative standard deviation of $\sigma_{s}, 550$ is $68 \%$ without the 23-25 July data and 104\% with all the data included. Thus some of the large variation in the observed extensive parameters can be attributed to the intense smoky period. However, even with this period excluded, the variation in the data remains high.

Figure 4 summarizes the statistical distribution of the nephelometer data for the whole campaign, excluding 23-25 July. The mean and median values are represented by the dot and line in the box, respectively, and the top and bottom of the box are the 75th and 25 th percentiles, respectively. The error bars indicate the 95th and 5th percentile. All similar statistical box plots shown in this paper will have the same structure. 


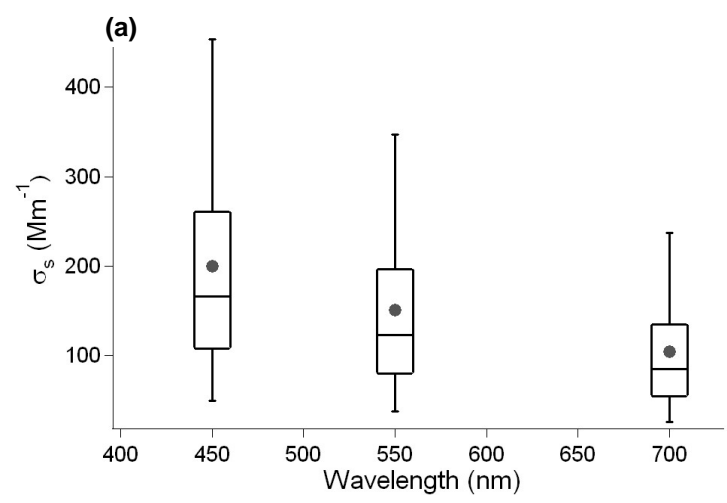

(b)

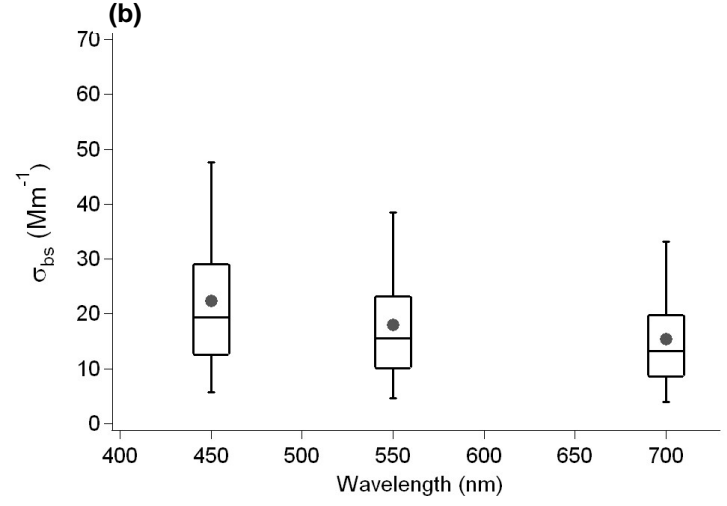

Fig. 4. Statistical distribution of (a) scattering coefficients $\left(\sigma_{s}\right)$ and (b) backscattering coefficients $\left(\sigma_{b s}\right)$ measured with the threewavelength nephelometer for the campaign (excluding 23-25 July). The dot is the mean value, the horizontal line in the box is the median, the limits of the boxes are the 25 th percentile and 75 th percentile and the vertical lines extend to 5th and 95th percentiles.

The mean values of the $\sigma_{s}$ and $\sigma_{b s}$ coefficients are generally well above the median value. For example, the mean value for $\sigma_{s}, 550\left(151 \mathrm{Mm}^{-1}\right)$ is $23 \%$ larger than the median value $\left(123 \mathrm{Mm}^{-1}\right)$. This difference indicates a non-Gaussian distribution of the data with some very large values (i.e., during pollution episodes).

\subsubsection{Intensive properties}

The Ångström exponent $\left(\stackrel{\circ}{a}_{s}\right)$, backscattering fraction $(b)$, and single scattering albedo $\left(\omega_{532}\right)$ time series are shown in Fig. 5. These parameters were calculated as described in Sect. 2.3. The major polluted period of the campaign, 2325 July, can be seen clearly in the backscattering fraction and Ångström exponent time series with a sudden decrease at the beginning of this time period and continued low values throughout the episode. This highlights the fact that the particles measured during this time had different optical properties from the rest of the campaign; again these data were removed from the discussion of the average optical properties. Figure 6 displays box plots for the campaign statistics of $b, \stackrel{\circ}{a}_{s}$ and $\sigma_{s, 532}, \sigma_{a, 532}$ and $\omega_{532}$. The mean values

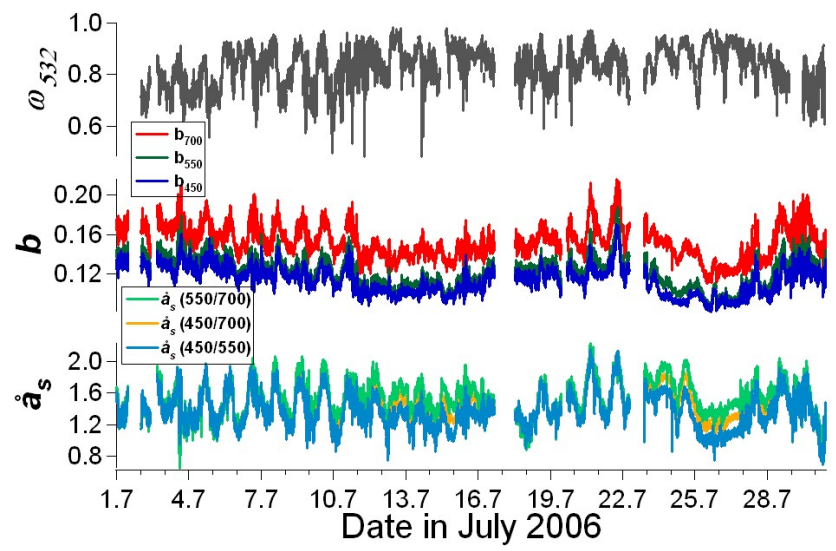

Fig. 5. Time series for the intensive optical properties calculated for different wavelengths and wavelength pairs, respectively: single scattering albedo $\left(\omega_{532}\right)$, backscattering fraction $(b)$ and Ångström exponent $\left(\stackrel{\circ}{a}_{S}\right)$.

and standard deviations of $b$ were $0.116 \pm 0.013(450 \mathrm{~nm})$, $0.124 \pm 0.015(550 \mathrm{~nm})$, and $0.154 \pm 0.017(700 \mathrm{~nm})$; and for $\stackrel{\circ}{a}_{s}$ were $1.51 \pm 0.22 \stackrel{\circ}{a}_{s}$ (550/700), $1.46 \pm 0.21 \stackrel{\circ}{a}_{s}(450 / 700)$ and $1.38 \pm 0.22 \stackrel{\circ}{a}_{s}(450 / 550)$. As seen in Fig. $6 \mathrm{a}$ and b, both $b$ and $\stackrel{\circ}{a}_{s}$ were dependent on wavelength. While $b$ increased with increasing wavelength due to decreasing size parameters, $\stackrel{\circ}{a}_{s}$ increased for the longer wavelength pairs due to curvature in the $\log \left(\sigma_{s} / \mathrm{Mm}^{-1}\right)$ vs. $\log (\lambda / \mathrm{nm})$ plot. The latter will be discussed in detail in Sect. 3.4.3.

In Fig. 6c, the calculated $\sigma_{s, 532}$ and measured $\sigma_{a, 532}$ values are displayed. These two coefficients were used to calculate $\omega_{532}$, which is also shown in Fig. 6c. The mean and standard deviation of $\sigma_{s, 532}$ for the campaign was $158 \pm 108 \mathrm{Mm}^{-1}$, slightly larger than the measured $\sigma_{s, 550}$. The mean and standard deviation for $\omega_{532}$ for the campaign was $0.82 \pm 0.07$. Note that for the intensive parameters $b, \stackrel{\circ}{a}_{s}$ and $\omega_{532}$ the relative standard deviations are small $(\leq 16 \%)$ compared to the extensive parameters $\left(\sigma_{s}\right.$ and $\left.\sigma_{a}\right)$ and the distribution is symmetric, i.e., the mean and median values are similar (within $2 \%$ ). This suggests that most of the observed variation in the extensive optical properties was due to changes in the particle concentration rather than in changes in the intrinsic properties of the particles.

During the "intense smoky period" (23-25 July), the Ångström exponent increased for two of the wavelength pairs $(+8 \%$ for $550 / 700 \mathrm{~nm},+3 \%$ for $450 / 700 \mathrm{~nm})$, but decreased for the third pair $(-4 \%$ for $450 / 550 \mathrm{~nm})$. These differences can be explained by increased curvature and will be discussed in Sect. 3.4.3. The single scattering albedo increased during this time to 0.88 , which is common in smoldering fires and may be due to a decrease in the proportion of absorbing material or changes in particle size distribution, or both (Reid, 1998); this will be discussed in more detail in Sect. 3.4.2. Due to the strong local emissions from fires surrounding the measurement site and low wind speeds 
Table 2. Aerosol particle scattering coefficients, absorption coefficients and single scattering albedo values observed in this study and reported for select other campaigns (arithm. mean \pm std. dev.). TSP=total suspended particles.

\begin{tabular}{|c|c|c|c|c|c|c|c|}
\hline Location & $\lambda(\mathrm{nm})$ & $\sigma_{s}\left(\mathrm{Mm}^{-1}\right)$ & $\sigma_{a}\left(\mathrm{Mm}^{-1}\right)$ & $\omega$ & RH & Inlet & cite \\
\hline This study & $\sigma_{s}=550 \sigma_{a}=532$ & $151 \pm 103$ & $34.3 \pm 26.5$ & $0.82 \pm 0.07$ & $<40 \%$ & $\mathrm{PM}_{10}$ & \\
\hline Beijing & $\sigma_{s}=530 \sigma_{a}=565$ & $488 \pm 370$ & $83 \pm 40$ & $0.84 \pm 0.08$ & $<40 \%$ & TSP(?) & Bergin et al. (2001) \\
\hline Xianghe & $\sigma_{s}=550 \sigma_{a}=550$ & $468 \pm 472$ & $65 \pm 75$ & $0.81-0.85$ & $<42.5 \%$ & TSP & Li et al. (2007) \\
\hline PRIDE-PRD2004 Guangzhou & $\sigma_{s}=545 \sigma_{a}=532$ & $463 \pm 178$ & $92 \pm 62$ & $0.839 \pm 0.050$ & $<45 \%$ & $\mathrm{PM}_{2.5}$ & Andreae et al. (2008) \\
\hline Linan (Yangtze delta) & $\sigma_{s}=530 \sigma_{a}=565$ & $353 \pm 202$ & $23 \pm 14$ & $0.93 \pm 0.04$ & $<40 \%$ & $\mathrm{PM}_{2.5}$ & Xu et al. (2002) \\
\hline ACE-Asia (Dust-Frontal) & $\sigma_{s}=550 \sigma_{a}=550$ & $330 \pm 31$ & $14 \pm 7.0$ & $0.96 \pm 0.02$ & $55 \%$ & $\mathrm{PM}_{10}$ & Quinn et al. (2004) \\
\hline Kwangju, Korea & $\sigma_{s}=520 \sigma_{a}=880$ & $319 \pm 222$ & $42 \pm 12$ & $0.84-0.93$ & ambient & $\mathrm{PM}_{10}$ & Kim et al. (2004) \\
\hline Xinken (PRD) & $\sigma_{s}=550 \sigma_{a}=630$ & $333 \pm 138$ & $70 \pm 42$ & & $<20 \%$ & $\mathrm{PM}_{10}$ & Cheng et al. (2008b) \\
\hline ACE-Asia (Dust+Shanghai) & $\sigma_{s}=550 \sigma_{a}=550$ & $202 \pm 63$ & $17 \pm 6.5$ & & $55 \%$ & $\mathrm{PM}_{10}$ & Quinn et al. (2004) \\
\hline ACE-Asia (volcano + polluted) & $\sigma_{s}=550 \sigma_{a}=550$ & $188 \pm 67$ & $9.0 \pm 3.0$ & & $55 \%$ & $\mathrm{PM}_{10}$ & Quinn et al. (2004) \\
\hline Baltimore, USA (smoke) & $\sigma_{s}=530$ & $126 \pm 80$ & & & ambient & TSP & Adam et al. (2004) \\
\hline Atlanta & $\sigma_{s}=530 \sigma_{a}=550$ & $121 \pm 48$ & $16 \pm 12$ & $0.87 \pm 0.08$ & $48 \pm 5 \%$ & $\mathrm{PM}_{2.5}$ & Carrico et al. (2003) \\
\hline ACE-Asia (Dust+Korea) & $\sigma_{s}=550 \sigma_{a}=550$ & $120 \pm 57$ & $8.4 \pm 2.5$ & & $55 \%$ & $\mathrm{PM}_{10}$ & Quinn et al. (2004) \\
\hline ACE-Asia (polluted-Japan) & $\sigma_{s}=550 \sigma_{a}=550$ & $114 \pm 16$ & $11 \pm 2.1$ & $0.91 \pm 0.01$ & $55 \%$ & $\mathrm{PM}_{10}$ & Quinn et al. (2004) \\
\hline Negev Desert, Israel & $\sigma_{s}=550$ & $86.7 \pm 53.8$ & & & ambient & TSP & Andreae et al. (2002) \\
\hline ACE-Asia (airborne) & $\sigma_{s}=550 \sigma_{a}=550$ & $83.3 \pm 100.6$ & $7 \pm 8.3$ & $0.923 \pm 0.032$ & $<40 \%$ & TSP & Anderson et al. (2003) \\
\hline ACE-Asia (polluted-Korea/Japan) & $\sigma_{s}=550 \sigma_{a}=550$ & $69 \pm 11$ & $7.9 \pm 1.5$ & & $55 \%$ & $\mathrm{PM}_{10}$ & Quinn et al. (2004) \\
\hline NEAQS-ITCT (NE US) & $\sigma_{s}=550$ & $42.9 \pm 35.2$ & & $0.92 \pm 0.06$ & $26 \pm 4 \%$ & $\mathrm{PM}_{1}$ & Wang et al. (2007) \\
\hline Yosemite Valey, USA & $\sigma_{s}=530$ & $37.28 \pm 28.99$ & & & “dry” & $\mathrm{PM}_{10}$ & Malm et al. (2005) \\
\hline Baltimore, USA (pre-smoke) & $\sigma_{s}=530$ & $32 \pm 19$ & & & ambient & TSP & Adam et al. (2004) \\
\hline ACE-Asia (marine) & $\sigma_{s}=550 \sigma_{a}=550$ & $29 \pm 17$ & $0.79 \pm 0.71$ & $0.97 \pm 0.03$ & $55 \%$ & $\mathrm{PM}_{10}$ & Quinn et al. (2004) \\
\hline ACE1 & $\sigma_{s}=550$ & $23 \pm 16$ & & 0.9 & $30-45 \%$ & $1 \mu \mathrm{m}-10 \mu \mathrm{m}$ & Quinn et al. (1998) \\
\hline Pacific NW, USA (North America Continental) & $\sigma_{s}=550 \sigma_{a}=550$ & $10.79 \pm 5.33$ & $1.39 \pm 0.54$ & $0.886 \pm 0.031$ & $<40 \%$ & $\mathrm{PM}_{1}$ & Anderson et al. (1999) \\
\hline Pacific NW, USA (Asian modified marine) & $\sigma_{s}=550 \sigma_{a}=550$ & $8.57 \pm 6.27$ & $0.08 \pm 0.12$ & $0.909 \pm 0.007$ & $<40 \%$ & $\mathrm{PM}_{1}$ & Anderson et al. (1999) \\
\hline Cape D’Aquilar, SE Hong Kong (July 1998) & $\sigma_{s}=530 \sigma_{a}=565$ & 7.62 & 4.05 & & $<60 \%$ & TSP(?) & Man and Shih (2001) \\
\hline Pacific NW, USA (North America modified marine) & $\sigma_{s}=550 \sigma_{a}=550$ & $6.49 \pm 5.31$ & $0.80 \pm 0.98$ & $0.895 \pm 0.059$ & $<40 \%$ & $\mathrm{PM}_{1}$ & Anderson et al. (1999) \\
\hline Baltimore, USA (post-smoke) & $\sigma_{s}=530$ & $6 \pm 3$ & & & ambient & TSP & Adam et al. (2004) \\
\hline ACE1 & $\sigma_{s}=550$ & $4.4 \pm 3$ & & & $30-45 \%$ & $\mathrm{PM}_{1}$ & Quinn et al. (1998) \\
\hline Pacific NW, USA (Marine) & $\sigma_{s}=550 \sigma_{a}=550$ & $3.34 \pm 2.31$ & $0.09 \pm 0.13$ & $0.974 \pm 0.034$ & $<40 \%$ & $\mathrm{PM}_{1}$ & Anderson et al. (1999) \\
\hline Equatorial Pacific Ocean & $\sigma_{s}=530 \sigma_{a}=565$ & $3.2 \pm 2.41$ & $0.6 \pm 0.05$ & $0.976 \pm 0.01$ & $65 \pm 4 \%$ & $\mathrm{PM}_{2}$ & Fujitani et al. (2007) \\
\hline
\end{tabular}

(stagnation), the intensive parameters determined during the "intense smoky period" can be considered to represent the optical properties of emissions from the burning of plant farming waste.

\subsubsection{Comparison to earlier measurement campaigns}

Table 2 summarizes the scattering and absorption coefficients and single scattering albedos observed in this study and in select other studies with comparable instrumentation and measurement conditions (Quinn et al., 1998; Anderson et al., 1999; Bergin et al., 2001; Man and Shih, 2001; Andreae et al., 2002; Xu et al., 2002; Anderson et al., 2003; Adam et al., 2004; Kim et al., 2004; Quinn et al., 2004; Malm et al., 2005; Fujitani et al., 2007; Li et al., 2007; Wang et al., 2007; Andreae et al., 2008; Cheng et al., 2008b). Studies not reporting the detailed measurement conditions were not included in this comparison.

The measured $\sigma_{s, 550}$ values at the Backgarden site (this campaign) are lower than most measurements made in urban areas in Asia; however, they are still larger than results from many other urban areas (e.g., Baltimore and Atlanta). The average $\sigma_{a}$ from this study is also smaller than the $\sigma_{a}$ measured in large urban areas in Asia, though similar to urban areas elsewhere. Since the concentrations of black carbon (BC) in Southern China are normally at their lowest in sum- mer (Streets et al., 2003; Cheng et al., 2006a), the average absorption values measured in this campaign may represent the annual low for this area.

Note that the $\sigma_{s}$ and $\sigma_{a}$ measured at Cape D'Aguilar (southeast tip of Hong Kong, air masses measured came off South China Sea) July 1998 are similar to background marine values elsewhere and are significantly smaller than those measured at Backgarden (Man and Shih, 2001). This indicates that the air masses coming off of the South China Sea are indeed clean and accumulate aerosol pollution as they cross Hong Kong and the rest of the PRD region. It is unclear why the $\sigma_{a}$ values in Man and Shih (2001) are so high relative to $\sigma_{s}$, though this may be due to possible instrumentation issues with the PSAP. Regardless, the extensive properties increase dramatically after passing over the PRD region; this will be discussed in more detail in Sect. 3.3.

Compared to the other campaigns listed in Table 2 the $\omega$ values measured in Backgarden are among the lowest, indicating darker (i.e., more highly absorbing) aerosols and a higher relative abundance of light absorbing carbon and combustion sources in the PRD. 
3.1.4 Comparison with remote sensing data and possible impact of relative humidity

Aerosol optical properties depend on particle size and composition, which can be greatly influenced by hygroscopic growth (Mikhailov et al., 2006; Garland et al., 2007). Thus, it is critical to control the relative humidity when measuring aerosol optical parameters. In PRIDE-PRD2006, and most other earlier studies of aerosol optical properties with comparable instrumentation (Table 2), the aerosols were dried to ensure constant measurement conditions and comparability. Extrapolation of the parameters measured under dry conditions to varying atmospheric conditions is not trivial.

To investigate this aspect and better characterize the aerosol optical properties of the region, the ground-based PRIDE-PRD2006 data have been compared to AERONET remote sensing data retrieved for the Backgarden site (available for July 1, 2, 5, 11-13, 18-25, 27). The AERONET single scattering albedo $\left(\omega_{532}\right)$ daily averaged values were +0 0.19 larger (on average +0.11 ) than for the dry ground-based $\omega_{532}$ values. These AERONET data are for the whole column and at ambient conditions, so the difference between our $\omega_{532}$ values and the AERONET values would be due to a combination of these effects. The impact of humidification on $\omega_{532}$ can also be modeled, but the model results depend upon particle size and composition, its refractive index and the mixing state of the aerosol particle; additionally, it is not clear how absorbing aerosols are impacted by humidification (Nessler et al., 2005; Mikhailov et al., 2006). The impact of humidification on the aerosol optical properties was modeled using the dry aerosol optical property measurements in PRIDEPRD2004 in October 2004 at a site southeast of Guangzhou. In this study, Cheng et al. (2008a), found a $<10 \%$ increase in $\omega_{532}$ from $30 \% \mathrm{RH}$ to $80 \% \mathrm{RH}$, which are approximately the measurement and ambient $\mathrm{RH}$, respectively, for this current study. Additionally, the impact of hygroscopic growth on the aerosol scattering coefficient was measured for the urban site in downtown Guangzhou as part of PRIDE-PRD2006; the impact of $\mathrm{RH}$ on the absorption coefficient of the particles was neglected (Liu et al., 2008). Applying these hygroscopicity results to the Backgarden measurements, the $\omega_{532}$ for the Backgarden site would increase by $+0.01-0.23$ (average of +0.10 ) from $40 \% \mathrm{RH}$ to $80 \% \mathrm{RH}$. As can be seen from these two studies from the PRD region, the impact of relative humidity on the aerosol optical properties is highly variable and further investigations with improved techniques (simultaneous absorption and scattering measurements at different $\mathrm{RH}$ levels) will be required for a comprehensive and reliable characterization. (a)
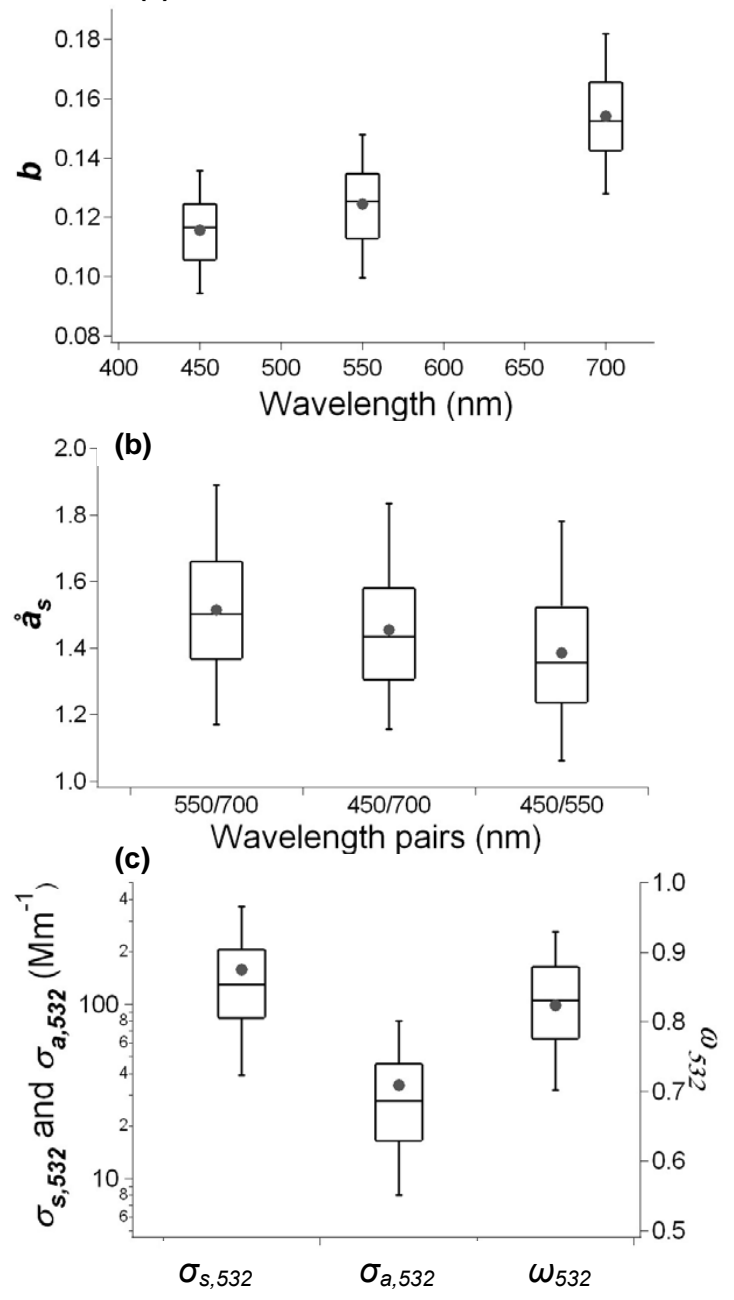

Fig. 6. Statistical distribution of (a) backscattering fraction $(b)$ for different wavelengths, (b) Ångström exponent $\left(\stackrel{\leftrightarrow}{a}_{S}\right)$ for different wavelength pairs, and (c) scattering and absorption coefficient and single scattering albedo at $532 \mathrm{~nm}\left(\sigma_{s, 532}, \sigma_{a, 532}, \omega_{532}\right)$ for the campaign (excluding 23-25 July). Symbols are analogous to Fig. 4.

\subsection{Diurnal variations}

The $\sigma_{s}, \sigma_{a} \omega_{532}$ and $\stackrel{\circ}{a}_{s}$ values were found to have pronounced diurnal variations. Figure $7 \mathrm{a}$ and $\mathrm{b}$ displays the statistics for the normalized $\sigma_{s, 550}$ and $\sigma_{a, 532}$. To normalize the data, each measured value was divided by its respective 24-h average (arithmetic mean) on the day of measurement. Thus, in Fig. $7 \mathrm{a}$ and $\mathrm{b}$, a value of one indicates the daily average. The $\sigma_{s, 550}$ was elevated during the nighttime with a maximum mean value of 1.2 (20:00-22:00). Both the mean and median values then fall below one between 08:00 and 18:00 with a minimum mean value of $\sim 0.8$ between 09:00 and 14:00. Figure $7 \mathrm{~b}$ displays the diurnal cycle for $\sigma_{a, 532}$, which is even more pronounced than that of $\sigma_{s, 550}$. Again, both the mean and median values were enhanced at night with maximum 
(a)

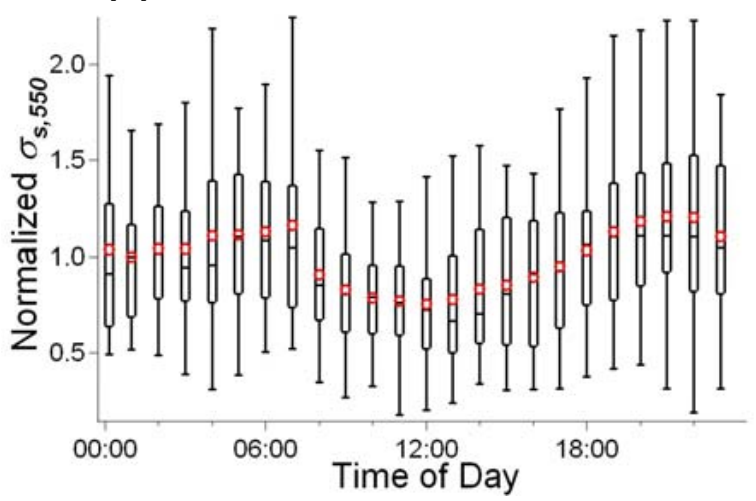

(c)

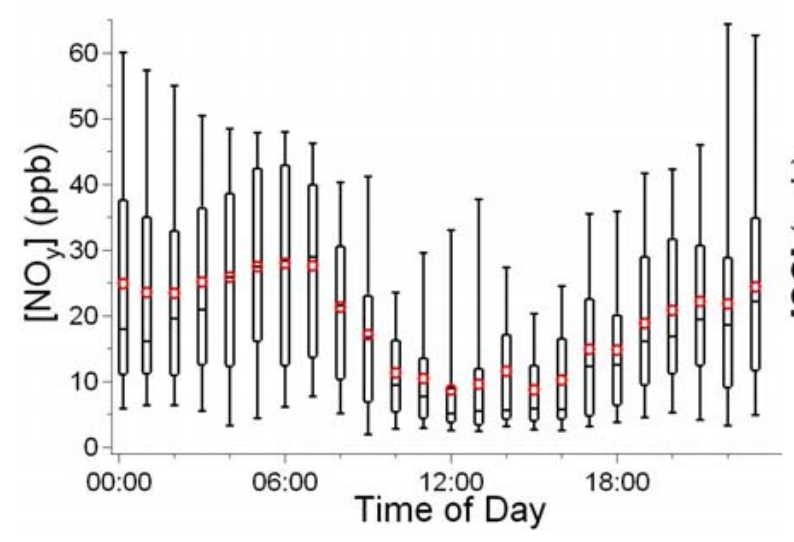

(b)

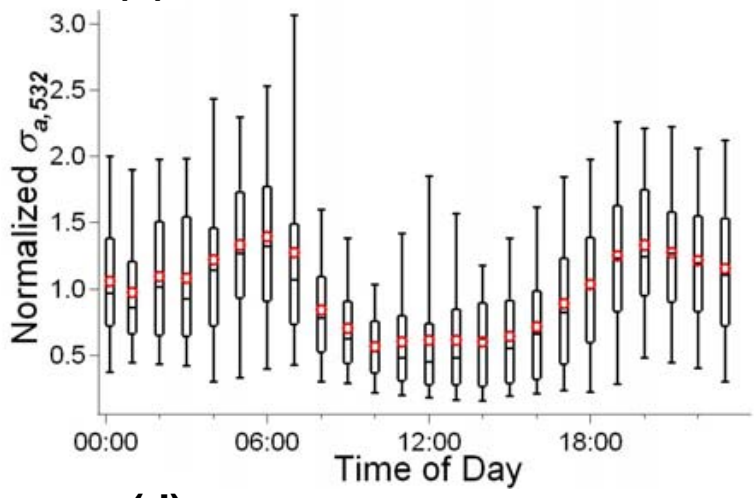

(d)

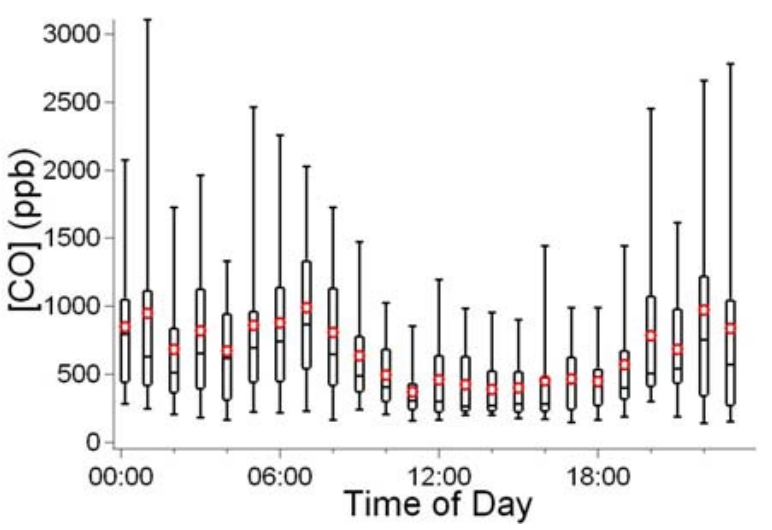

Fig. 7. Diurnal cycles of normalized scattering and absorption coefficients in the green spectral range and volume mixing ratios of total reactive nitrogen and carbon monoxide averaged over the campaign (excluding 23-25 July): (a) normalized $\sigma_{s, 550}$, (b) normalized $\sigma_{a, 532}$, (c) $\left[\mathrm{NO}_{\mathrm{y}}\right]$ and (d) $[\mathrm{CO}]$. The dot is the mean value, the horizontal line in the box is the median, the limits of the boxes are the 25 th percentile and 75 th percentile and the vertical lines extend to 5 th and 95 th percentiles for each 1 -h period after the indicated start time.

hourly mean values of $1.3(19: 00-21: 00)$ and $1.4(06: 00)$. The mean and median values then fall below one between 08:00 and 18:00 with a minimum hourly mean value of $\sim 0.6$ between 10:00 and 15:00.

For comparison, Fig. 7c and d displays the diurnal cycles of the gas phase concentrations of $\mathrm{NO}_{\mathrm{y}}$ and $\mathrm{CO}$, respectively. Both exhibited similar cycles with minima during the day and maxima at night with a build-up evident before sunrise and a sharp decrease around sunrise (06:00-08:00). Similar to the $\sigma_{a, 532}$ cycle, the daytime minimum concentration of $\mathrm{CO}$ was on average $\sim 40 \%$ lower than the corresponding $24-$ $\mathrm{h}$ mean value. The $\mathrm{NO}_{\mathrm{y}}$ daytime minimum concentration was on average $\sim 50 \%$ lower than the 24 -h mean.

Most likely, the diurnal cycles of $\sigma_{s, 550}, \sigma_{a, 532}, \mathrm{NO}_{\mathrm{y}}$, and $\mathrm{CO}$ were dominated by convective mixing during the daytime, which leads to a dilution and decrease in $\sigma_{s, 550}, \sigma_{a, 532}$ and trace gas concentrations. After sunset, the formation of a stable nocturnal boundary layer (BL) in combination with the continued emission or advection of particles and trace gases throughout the night, leads to an increase in $\sigma_{s, 550}, \sigma_{a, 532}$ and gas phase concentrations. As this measurement campaign was in the summer, it is unlikely that the increase observed in the evening was caused by an increase of local or regional emissions from biomass burning or heating fuel combustion. While there were no local rush hours with enhanced traffic emissions, it is evident from Fig. 1 that the site is only some $10 \mathrm{~km}$ downwind of densely populated and industrialized areas of the Guangzhou urban area. Since truck traffic, dominated by high-emission diesel vehicles, increases sharply at night as a result of local traffic regulations (Bradsher, 2007), increased diesel emissions in the upwind area must be expected and probably contribute to the evening increase in pollutants at our site. Thus, the diurnal cycle of the extensive optical properties appears to be driven by the changes in the boundary layer in combination with enhanced diesel emissions at night. 
(a)

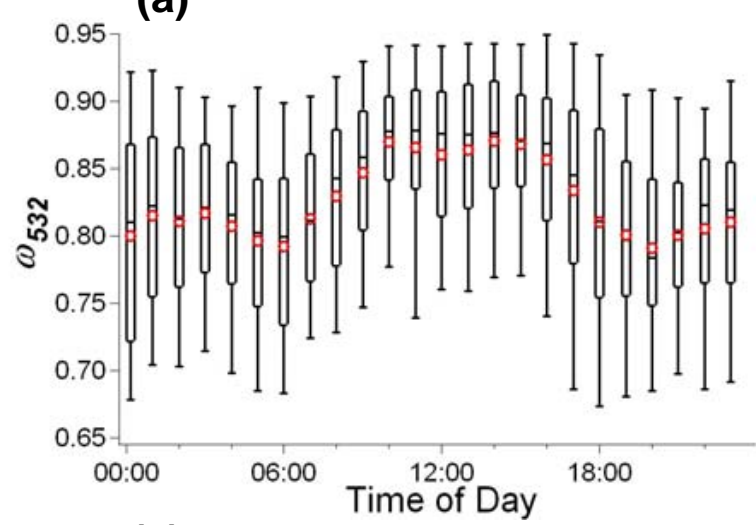

(c)

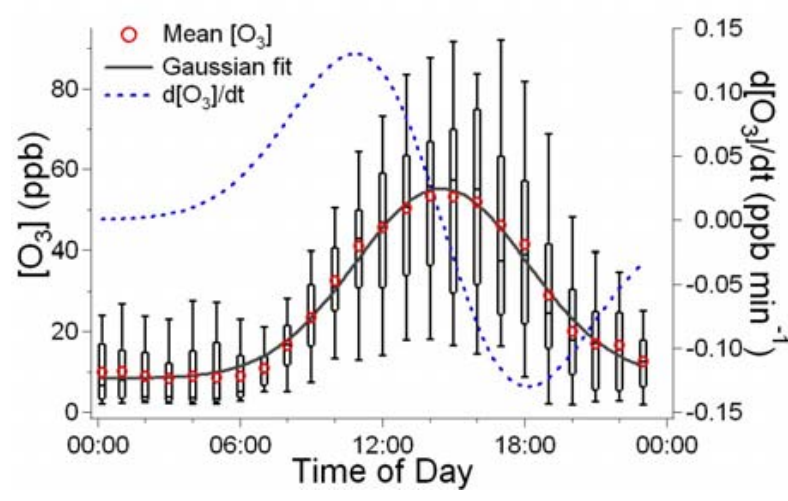

(b)

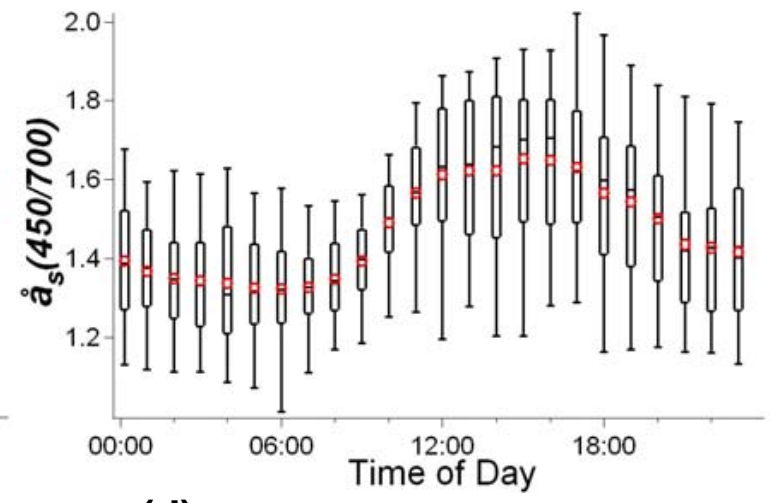

(d)

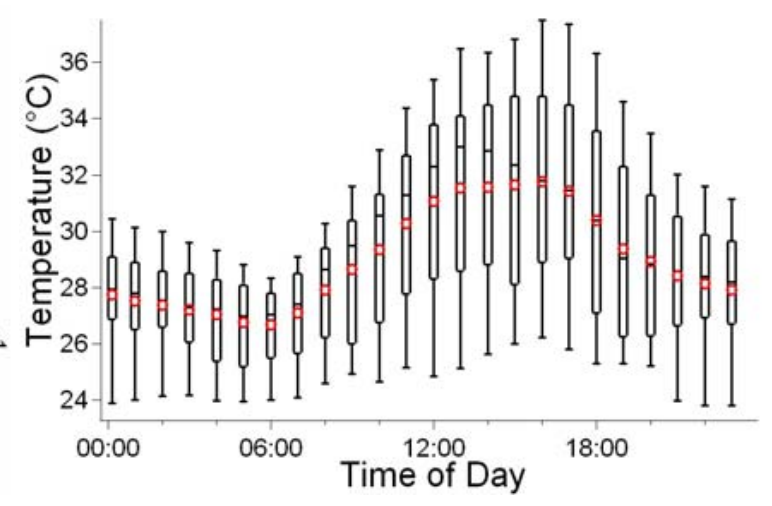

Fig. 8. Diurnal cycles of single scattering albedo, Ångström exponent, ozone volume mixing ratio and production rate, and ambient temperature averaged over the campaign (excluding $23-25$ July): (a) $\omega_{532}$, (b) $\stackrel{\circ}{a}_{S}(450 / 700)$, (c) $\left[\mathrm{O}_{3}\right]$ and $d\left[\mathrm{O}_{3}\right] / d t$ and (d) temperature. Symbols are analogous to Fig. 7.

As seen in Fig. 8a, the diurnal cycle observed for $\omega_{532}$ is a mirror image of the $\sigma_{a, 532}$ cycle. The maximum hourly mean values (0.86-0.87) occurred during the daytime (10:0014:00) and the minimum hourly mean values $(0.79-0.80)$ occurred in the morning (05:00-06:00) and evening (19:0020:00). Additionally, around sunrise (06:00-08:00) the $\omega_{532}$ values sharply increased, just as the $\sigma_{a, 532}$ and $\sigma_{s, 550}$ values sharply decreased, reached a plateau at 10:00 and stayed constant until 16:00.

If a combination of convective mixing and regional emissions is responsible for the diurnal cycle of $\omega_{532}$, it can be described by a simple conceptual mixing model (Fig. 9) (Keeling et al., 1996). One end-member of the mixing series would be the daytime aerosol particles present in the wellmixed BL at the middle of the day, the other an aerosol representing fresh emissions with a lower $\omega_{532}$. In a plot of $\sigma_{a, 532}$ vs. $\sigma_{s, 550}$, the hourly mean values would move from a daytime value, reflecting the BL average $\omega_{532}$, along a line with a slope defined by the $\omega_{532}$ of the fresh emissions, towards a set of points that represent the composition of the aerosol in the nocturnal BL (Fig. 9). The residual layer above the inversion would continue to contain the more highly aged daytime particles with a higher $\omega_{532}$. When convective mixing begins after sunrise, these two types of aerosols would mix, and the $\omega_{532}$ values measured through the morning would be a linear combination of the "night" aerosol particles with a low $\omega_{532}$ and the "day" aerosol particles with a high $\omega_{532}$. Any significant deviation from a straight mixing line would indicate addition (or removal) of an aerosol component with a different $\omega_{532}$ (e.g., by secondary aerosol formation). To test this assumption, the hourly mean $\sigma_{a, 532}$ and $\sigma_{s, 550}$ values were plotted in Fig. 9 (points are labeled as "time of day"). The average value of the 06:00 and 07:00 means (point $\mathrm{N}$ in Fig. 9) was assumed to represent the nighttime conditions before the onset of convective mixing, and the mean value at 12:00 (point D) was taken to be representative of the fully mixed daytime BL. Lines were fit through each of these points and forced through the origin. The slope of these lines, $a=d \sigma_{a, 532} / d \sigma_{s, 532}$, is related to $\omega_{532}$ by $\omega_{532}=1 /(a+1)$, and thus reflects the characteristic $\omega_{532}$ of the day and night aerosol. Figure 9 shows that all of the values during nighttime are clustered towards the top right around the 20:00 value. After sunrise, the values move down the mixing line to the 12:00 value, consistent with the 


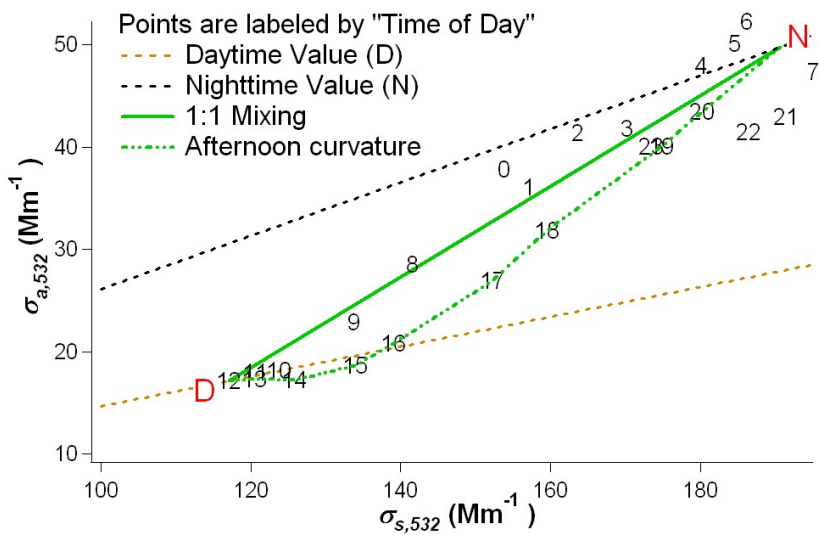

Fig. 9. Mixing diagram for $\sigma_{a, 532}$ and $\sigma_{s, 532}$ relationship. The characteristic day ratio (point D) is $12: 00$ and the characteristic night value is between 06:00 and 07:00 (point $\mathrm{N}$ ). The black and brown dotted lines are fit through each of these points and zero; the solid green line represents linear 1:1 mixing of " $\mathrm{D}$ " and " $\mathrm{N}$ " values. The dotted green line highlights the curvature seen in afternoon. Data points are arithmetic mean values averaged over the campaign (excluding 23-25 July) for 1-h periods after the indicated start time.

assumption that convective mixing can explain the morning drop in $\sigma_{a, 532}$ and $\sigma_{s, 532}$, as well as the concurrent drop in $\omega_{532}$.

The return path from $\mathrm{D}$ to $\mathrm{N}$ suggests a slight curvature, which may be related to local production of secondary aerosol mass in the early afternoon hours. However, the variability in the data does not permit a firm conclusion regarding the significance and amount of secondary aerosol production. At any rate, our results show no clear evidence of strong in situ production of secondary aerosol mass on a time scale of hours, and, within the experimental uncertainty, the observed behavior can be adequately explained by mixing of fresh emissions and aged aerosol. If we assume the data in Fig. 9 to represent only the mixing between one end-member representing a mixed regional BL aerosol and another representing fresh pollution, the single scattering albedo of this second component can be derived from the slope of the mixing line. Linear regression to the data yields a slope of 0.44 corresponding to $\omega_{532}=0.69$ for the fersh emissions.

The diurnal cycle for $\stackrel{\circ}{a}_{s}(450 / 700)$ is displayed in Fig. $8 \mathrm{~b}$. The mean values have a minimum of 1.33 in the morning (05:00-07:00) and a maximum value of 1.65 in the afternoon (15:00-16:00). It indicates that the aerosol particles were on average smaller in the afternoon, which might be due to new particle formation or temperature-related gas-particle partitioning effects.

For comparison, Fig. 8c and d displays the diurnal cycles of ozone and ambient temperature, respectively. Additionally, Fig. 8c displays the rate of change in $\left[\mathrm{O}_{3}\right]$ as a function of time, which can be considered an indication of photochemical activity. This rate was calculated by fitting a Gaussian curve to the mean hourly $\left[\mathrm{O}_{3}\right]$ (shown in Fig. 8c) and taking the derivative of the fit. This is reported in $\mathrm{ppb} \mathrm{min}^{-1}$ by the dotted line on Fig. 8c and indicates that the photochemical activity (represented here by $d\left[\mathrm{O}_{3}\right] / d t$ ) is highest before noon, while the concentration of ozone is highest in the early afternoon. Note that this peak in ozone concentration corresponds to both the increased scattering seen in the afternoon in Fig. 9 as well as the peak in the $\stackrel{\circ}{a}_{s}$ cycle. If secondary aerosol production is responsible for the afternoon increase of scattering and decrease of average particle size, then this production is not occurring at the peak of photochemical activity, but rather at the peak of $\left[\mathrm{O}_{3}\right]$. Additionally, the $\stackrel{\circ}{a}_{s}$ cycle is similar to the temperature diurnal cycle. It is possible that the temperature increase might lead to a reduction of particle size by evaporation of semi-volatile components. However, further investigations into the diurnal cycle of the aerosol size distributions and composition as well as detailed modeling of the gas phase and heterogeneous chemistry will be required to fully elucidate the diurnal cycle of $\stackrel{\circ}{a}_{s}$. During the campaign there was a tropical storm, Bilis (15 to 17 July), a typhoon, Kaemi (25 July, 21:00 to 27 July) and one large rain event (10 July, 13:15 to 11 July, 19:00). These periods may change the aerosol properties and thus may influence the apparent diurnal patterns. When excluding these periods, the mean and median values of the $\omega_{532}$ and $\stackrel{\circ}{a}_{s}$ changed by less than $2 \%$, and the diurnal cycles did not change at all. For the purpose of radiative calculations in climate models, the $\omega_{532}$ of average dry aerosol particles in the PRD region appears best represented by the daytime average value of 0.87 (also represented by the line from the origin through point $\mathrm{D}$ in Fig. 9), which is somewhat higher than the 24-h average of 0.82 (Tables 1 and 2). The daytime measurements most closely reflect the mean composition of the boundary layer and represent the aerosol that actually interacts with the solar radiation.

\subsection{Relationship with wind direction and air mass trajecto- ries}

The local wind direction and wind speed $(v)$ were measured by a Vaisala Weather Transmitter (WXT510; operated by University of Tokyo). Figure 10 shows the relationship of $\sigma_{s, 550}$ and $\omega_{532}$ to local wind direction and local wind speed. On these graphs, Guangzhou would be $\sim 157^{\circ}$. Figure 10a is wind direction versus wind speed, with $\sigma_{s, 550}$ as the color scale. No strongly evident relationship was seen between $\sigma_{s, 550}$ (and $\sigma_{a, 532}$, though not shown) and local wind direction. On average, both $\sigma_{s, 550}$ and $\sigma_{a, 532}$ were lower during periods with above average local wind speeds (wind speed $(v) \geq 2 \mathrm{~m} \mathrm{~s}^{-1}$ ). When $v<2 \mathrm{~m} \mathrm{~s}^{-1}$, the average $\sigma_{s, 550}$ was $128 \mathrm{Mm}^{-1}$ compared to $82 \mathrm{Mm}^{-1}$ when $v \geq 2 \mathrm{~m} \mathrm{~s}^{-1}$. Similarly, $\sigma_{a, 532}$ was higher when $v<2 \mathrm{~m} \mathrm{~s}^{-1}$ with an average value of $42 \mathrm{Mm}^{-1}$ compared to $21 \mathrm{Mm}^{-1}$ when $v \geq 2 \mathrm{~m} \mathrm{~s}^{-1}$. Many of these instances of high wind speed were during storms when rain was also present. 
Table 3. Extensive and intensive aerosol optical properties for the days highlighted in Fig. 11 (daily arithm. mean \pm std. dev.). The "Back Trajectory" column provides a short description for this day's air mass.

\begin{tabular}{lllllll}
\hline Date & Back trajectory & $\sigma_{s, 550}\left(\mathrm{Mm}^{-1}\right)$ & $\sigma_{a, 532}\left(\mathrm{Mm}^{-1}\right)$ & $\stackrel{\circ}{S}_{s}(450 / 700)$ & $b_{550}$ & $\omega_{532}$ \\
\hline 12 July 2006 & Local from S, re-circulating, & $297 \pm 90$ & $53.8 \pm 42.3$ & $1.42 \pm 0.15$ & $0.107 \pm 0.006$ & $0.871 \pm 0.066$ \\
& & & & & \\
& & $263 \pm 203$ & $52.9 \pm 49.5$ & $1.41 \pm 0.14$ & $0.101 \pm 0.005$ & $0.846 \pm 0.055$ \\
13 July 2006 & Continental, W/NW & $228 \pm 84$ & $41.2 \pm 25.6$ & $1.65 \pm 0.27$ & $0.130 \pm 0.013$ & $0.868 \pm 0.048$ \\
20 July 2006 & Slow, SW & & & & \\
& & $201 \pm 112$ & $43.6 \pm 30.1$ & $1.63 \pm 0.25$ & $0.143 \pm 0.019$ & $0.846 \pm 0.040$ \\
21 July 2006 & Slow, S/SW & & & & \\
& & & & & \\
10 July 2006 & SE, large rain event (start 13:15) & $177 \pm 106$ & $50.7 \pm 40.7$ & $1.44 \pm 0.21$ & $0.125 \pm 0.012$ & $0.786 \pm 0.065$ \\
18 July 2006 & Marine, SE over PRD & $114 \pm 26$ & $25.8 \pm 11.1$ & $1.37 \pm 0.22$ & $0.126 \pm 0.006$ & $0.825 \pm 0.052$ \\
4 July 2006 & Marine, SE over PRD & $96.7 \pm 31.8$ & $34.3 \pm 15.4$ & $1.44 \pm 0.21$ & $0.139 \pm 0.008$ & $0.750 \pm 0.054$ \\
3 July 2006 & Marine, SE over PRD & $88.7 \pm 34.8$ & $31.0 \pm 16.7$ & $1.42 \pm 0.19$ & $0.141 \pm 0.010$ & $0.761 \pm 0.051$ \\
28 July 2006 & Marine, E & $86.5 \pm 40.3$ & $21.8 \pm 8.7$ & $1.60 \pm 0.15$ & $0.126 \pm 0.013$ & $0.806 \pm 0.048$
\end{tabular}

(a)

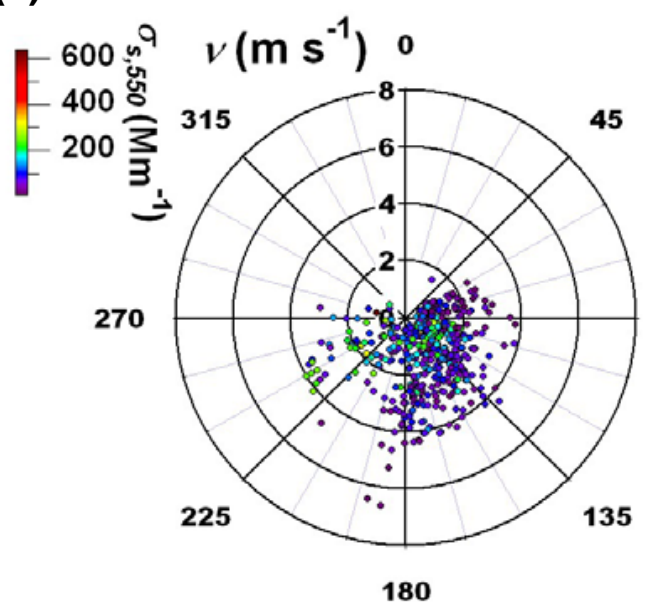

(b)

90

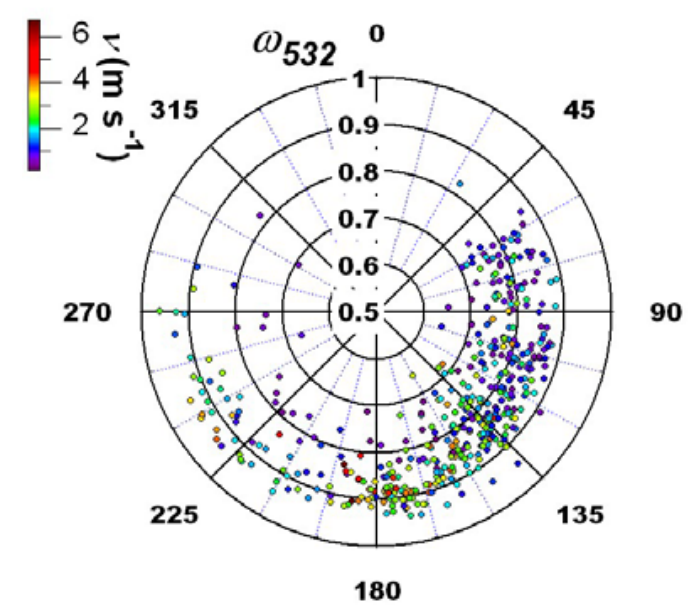

Fig. 10. Local wind direction and wind speed plots for the campaign (excluding 23-25 July): (a) wind direction versus wind speed ( $\mathrm{m} \mathrm{s}^{-1}$ ) with the color scale as $\sigma_{s, 550}\left(\mathrm{Mm}^{-1}\right)$ and $(\mathbf{b})$ wind direction versus $\omega_{532}$ with wind speed $\left(\mathrm{m} \mathrm{s}^{-1}\right)$ as the color scale. Each dot represents an optical measurement data point (averaging interval $=1 \mathrm{~h}$ ).

Figure $10 \mathrm{~b}$ displays wind direction versus $\omega_{532}$. The average $\omega_{532}$ values of $0.8-0.9$ are not strongly related to wind direction. However, the lower values of $0.6-0.8$ were seen mostly when the wind was coming from $45-180^{\circ}$, thus indicating a relationship between the low $\omega_{532}$ values and wind direction. When the local wind was coming from this direction, almost half (44\%) of the $\omega_{532}$ values recorded were in the range of $0.6-0.8$. This is compared to only $16 \%$ of the recorded $\omega_{532}$ values in the range of $0.6-0.8$ when the local wind was from the $180-45^{\circ}$ direction. This relationship with $\omega_{532}$ suggests that there may be a source of absorbing aerosols in this south/easterly $\left(45-180^{\circ}\right)$ direction, coinciding with the location of the densely populated urban region and high heavy-duty vehicle traffic (Fig. 1). Besides these weak relationships, no parameter was clearly related with local wind direction, indicating that the aerosol sources and pollution are regional in nature.

In order to probe the relationship of air mass origin and optical properties, nine days were chosen to represent the variety of wind trajectories that occurred throughout the campaign. Back trajectories were calculated with the NOAA Hysplit model (Draxler and Rolph, 2003) using FNL meteorological data (Stunder, 1997). Figure 11a displays the 24-h back trajectories (start: 24:00 local time, elevation: $100 \mathrm{~m}$ ) for these nine days. With the exception of 13 and 28 July, the calculated back trajectories were similar throughout the day 
(a)

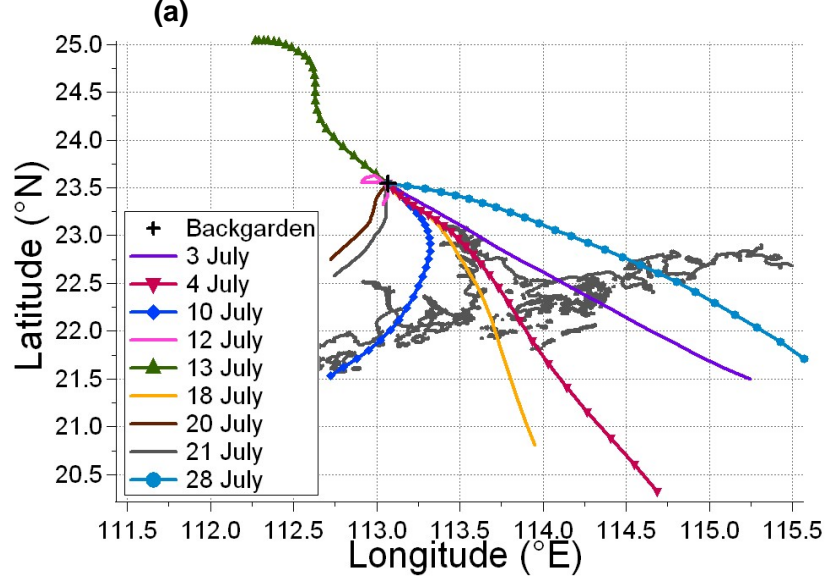

(b)

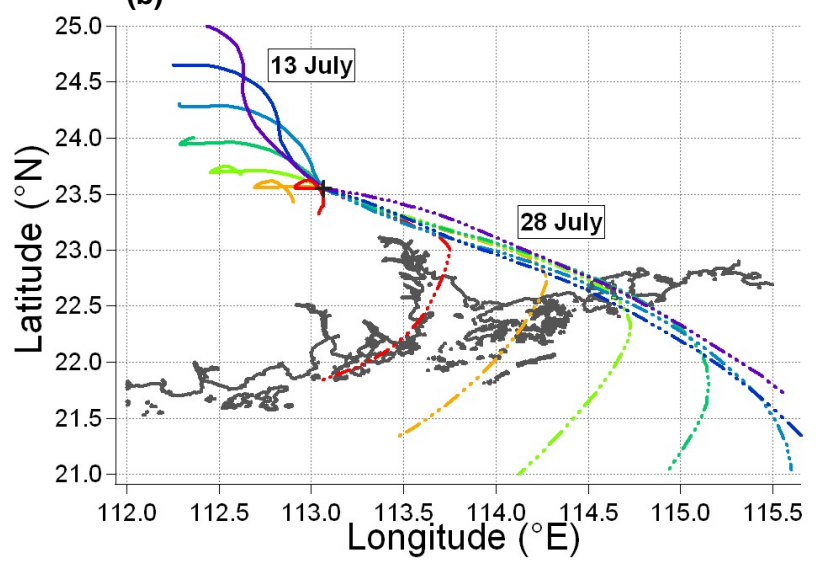

(c)

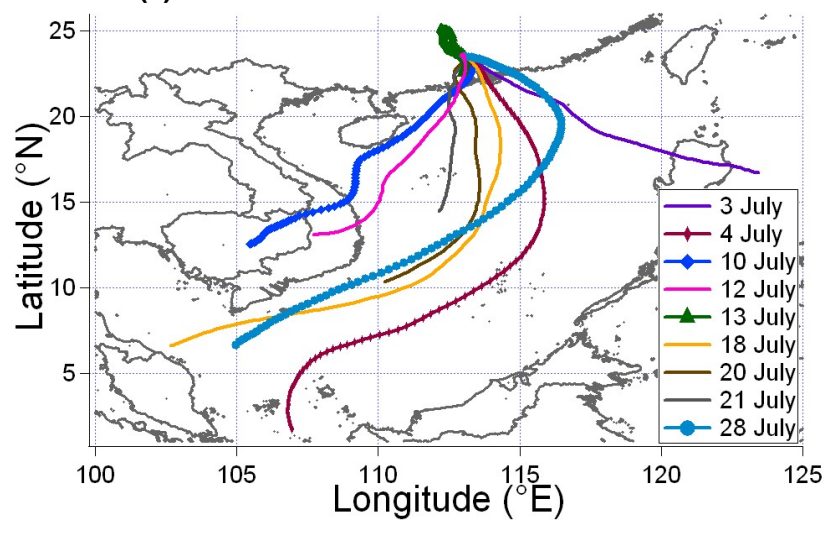

Fig. 11. Hysplit back trajectories for selected exemplary days: (a) 24-h back trajectories for all highlighted days (start time 24:00); (b) 24-h back trajectories for 13 July, solid lines, and 28 July, dotted lines, start times are purple $=24: 00$, dark blue $=20: 00$, light blue $=16: 00$, green $=12: 00$, light green $=08: 00$, orange $=04: 00$, red=00:00; (c) 4-day back trajectories for all highlighted days (start time 24:00). All times refer to local time and all trajectories had an initial elevation of $100 \mathrm{~m}$. (start times: 00:00-24:00). Back trajectories calculated every $4 \mathrm{~h}$ for 13 and 28 July are shown in Fig. $11 \mathrm{~b}$. For 13 July, the trajectory indicates that the air masses came from the west in the morning (red-light green) with a counterclockwise motion, and then moved to the north as the day continues. On 28 July, the air masses in the morning came from the coast, but moved farther out to sea as the day went on. Additionally, the trajectories on 12 July varied slightly (not shown). All trajectories on this day showed the air masses originating from the south of the measurement site; however the counterclockwise movement, as seen in Fig. 11a for this day, started at 15:00 local time. Before that time, the trajectories were calculated to come in directly from the south. Overall, $83 \%$ of the back trajectories calculated for the campaign originated from the south $\left(90-180^{\circ}\right)$.

Table 3 displays the daily averages of both extensive and intensive properties for these highlighted days. 12 July had the highest daily average for both $\sigma_{s}$ and $\sigma_{a}$. On this day there was a strong counterclockwise movement of the calculated trajectories, influenced by the incoming typhoon Bilis, indicating that these air masses moved slowly and more than once over the same local, continental sources. This combination of slow winds, repetitive crossings over pollution sources and $24 \mathrm{~h}$ over land led to a polluted air mass with the highest 24-h average $\sigma_{s}$ and $\sigma_{a}$ values.

In the morning of 13 July we observed the highest 2-min average scattering and absorption coefficients and the lowest single scattering albedo of the campaign (excluding 2325 July): $\sigma_{s, 550}=1132 \mathrm{Mm}^{-1}, \sigma_{a, 532}=305 \mathrm{Mm}^{-1}, \omega_{532}=0.48$. Note that this scattering coefficient is similar to the values reported from dust storms (e.g., $\sigma_{s, 530}=1139 \mathrm{Mm}^{-1}$ measured in Korea in the outflow of a dust storm in China; Kim et al., 2004).

13 July was one of only five days that had back trajectories originating from the north and were thus strongly influenced by continental sources. Additionally, as seen in Fig. 11b, there was also strong counterclockwise motion early in the day when the values were the highest (the red and green trajectories), indicating that, similar to 12 July, these air masses moved slowly over the same local sources.

Both 20 and 21 July were characterized by low wind speeds and back trajectories from the S/SW. 10 July has trajectories from $\mathrm{S} / \mathrm{SE}$ and there were also heavy rains in the afternoon, starting 13:15 and continuing until the next day. 3, 4, 18 and 28 July were unique in that their back trajectories showed both a higher wind speed and came directly off of the sea from the south and southeast. Also, 3, 4 and 18 July were calculated to pass over the urban Guangzhou/PRD region.

As seen in Table 3, when the air mass was over land for more than $24 \mathrm{~h}$ (i.e., 12, 13, 20 and 21 July), the extensive properties were the highest, indicating higher aerosol concentrations. When the air mass spent less than $24 \mathrm{~h}$ over land (3, 4, 18 and 28 July) the extensive optical properties were lower and were below the campaign averages (Table 1). During the same periods, the $\omega_{532}$ values also were lower than 
when the air mass spent more time over land. These low values of $\omega_{532}$ and the low extensive properties are consistent with measuring mainly primary emissions that are higher in absorbing material (e.g., soot); yet show lower extensive properties due to a short residence time over the source region (PRD). Man and Shih (2001) measured $\sigma_{s}$ and $\sigma_{a}$ on the southeastern tip of Hong Kong in July 1998 (as seen in Table 2) where air masses would pass as they came off of the South China Sea before crossing over the PRD region; the values they measured in July 1998 were up to thirteen times smaller than the Backgarden values, thus indicating that a large amount of particulate pollution is accumulated even in $<24 \mathrm{~h}$ over the PRD region. In contrast, the highest $\omega_{532}$ values were measured on 12 and 20 July when the air masses were slowly moving and hence residing longer over local continental sources, which resulted in elevated aerosol concentration (high extensive properties) and photochemical aging or secondary formation (high single scattering albedo). Wehner et al. (2008) saw in Beijing that the slower moving air masses generally contained larger modal particle diameters in the accumulation mode; this increase in size would tend to increase $\sigma_{s, 550}$ and $\omega_{532}$. However, as discussed below (Sect. 3.4.2), no strong relationship was seen in PRIDEPRD2006 between particle diameter and $\omega_{532}$, which thus indicates that the $\omega_{532}$ is driven by changes in composition and not in size distribution. In contrast to the extensive properties and $\omega_{532}$, both the $\stackrel{\circ}{a}_{s}$ and $b_{550}$ values did not show a strong dependence on either the direction or the time spent over land of the calculated back trajectories.

Figure 11c displays the 4-day back trajectories for the highlighted days (start time 24:00). As can be seen in Fig. 11c, the 4-day history of many of these air masses, except 13 July and 3 July, are all quite similar to each other. When the back trajectories were run with start times of 00:00-24:00 for the highlighted days that have air masses originating in the southwest, many of the trajectories overlapped, even though they have very different extensive and intensive properties. For example, the 4-day back trajectory for 12 July and 10 July are similar to each other, however, as seen in Table 3 their daily averaged extensive and intensive properties are very different. However, the days with the highest extensive properties (12, 13, 20 and 21 July) do have the slowest moving air masses. Thus, the 24-h history appears to drive both the extensive and intensive optical properties of the investigated air masses.

\subsection{Relationship with particle concentration and size}

\subsubsection{Scattering and absorption cross-section and effi- ciency}

The aerosol size distribution was measured from the same inlet as the aerosol optical measurements. The measured particle number size distribution averaged over the whole campaign, as well as the calculated surface area and volume

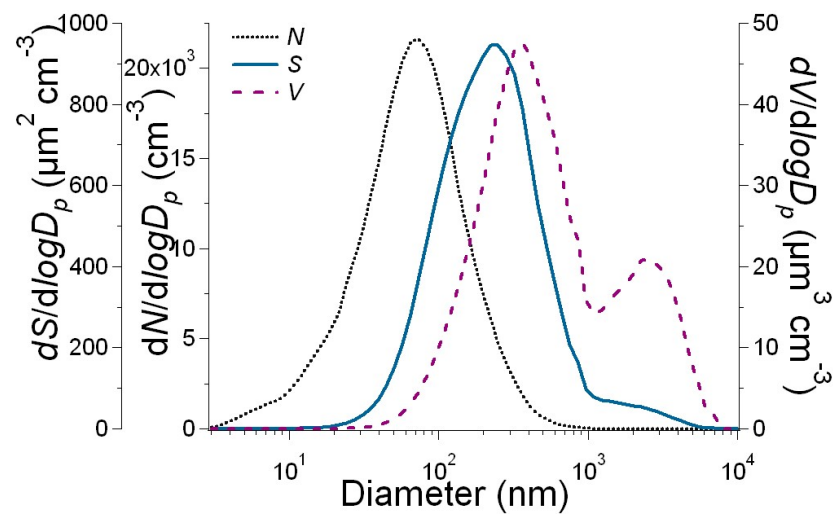

Fig. 12. Campaign average size distribution function of the particle number concentration $\left(d N / d \log D_{p}\right.$; black dotted line) as measured by TDMPS+APS (arithmetic mean, including 23-25 July). The surface area $\left(d S / d \log D_{p}\right.$; blue solid line) and volume $\left(d V / d \log D_{p}\right.$; purple dashed line) size distributions were calculated assuming spherical particles.

size distributions, assuming spherical particles, are shown in Fig. 12. The average mode diameters in the submicron size range were approximately $70 \mathrm{~nm}, 250 \mathrm{~nm}$, and $360 \mathrm{~nm}$, for the number, surface area and volume size distributions, respectively. The average volume mode diameter in the coarse fraction was $2.3 \mu \mathrm{m}$. The scattering and absorption coefficients plotted versus the number concentration of particles with diameters $\geq 100 \mathrm{~nm}\left(N_{100}\right)$ can be seen in Fig. 13a. The slopes of the reduced major axis (RMA (Ayers, 2001; Hammer et al., 2001)) best fit lines can be regarded as effective average cross-sections of the particles $D_{p} \geq 100 \mathrm{~nm}: 3.76 \pm 0.57 \times 10^{-14} \mathrm{~m}^{2}$ for scattering and $9.65 \pm 0.15 \times 10^{-15} \mathrm{~m}^{2}$ for absorption. According to Mie theory calculations, assuming a refractive index of 1.53$0.000 i$ (ammonium sulfate), this scattering cross-section value would correspond to a particle diameter of $\sim 250 \mathrm{~nm}$, which equals the modal diameter of the average surface area size distribution (Fig. 12). Figure 13b displays the scattering and absorption coefficients plotted versus surface area concentration for $\mathrm{PM}_{1}\left(D_{p} \leq 1 \mu \mathrm{m}\right)$. The slopes (multiplied by four) correspond to an average geometric scattering efficiency ( $\left.Q_{\text {scat }}\right)$ of 1.2 and absorption efficiency ( $\left.Q_{\text {abs }}\right)$ of 0.3 . These efficiencies are consistent with the effective average cross-sections and corresponding particle size determined from Fig. 13a, as well as with the campaign averaged single scattering albedo $(\omega \approx 0.8)$.

Figure $13 \mathrm{c}$ displays the scattering and absorption coefficients plotted versus $\mathrm{PM}_{10}$ mass concentrations calculated from the measured size distributions assuming an average density of ammonium sulfate $\left(1.7 \mathrm{~g} \mathrm{~cm}^{-3}\right)$. The slopes of the RMA fit lines can be regarded as the average $\mathrm{PM}_{10}$ mass scattering efficiency $\alpha_{s, \mathrm{PM}_{10}}=2.84 \mathrm{~m}^{2} \mathrm{~g}^{-1}$ and mass absorption efficiency $\alpha_{a, \mathrm{PM}_{10}}=0.74 \mathrm{~m}^{2} \mathrm{~g}^{-1}$, respectively. The scattering and absorption efficiencies 
(a)
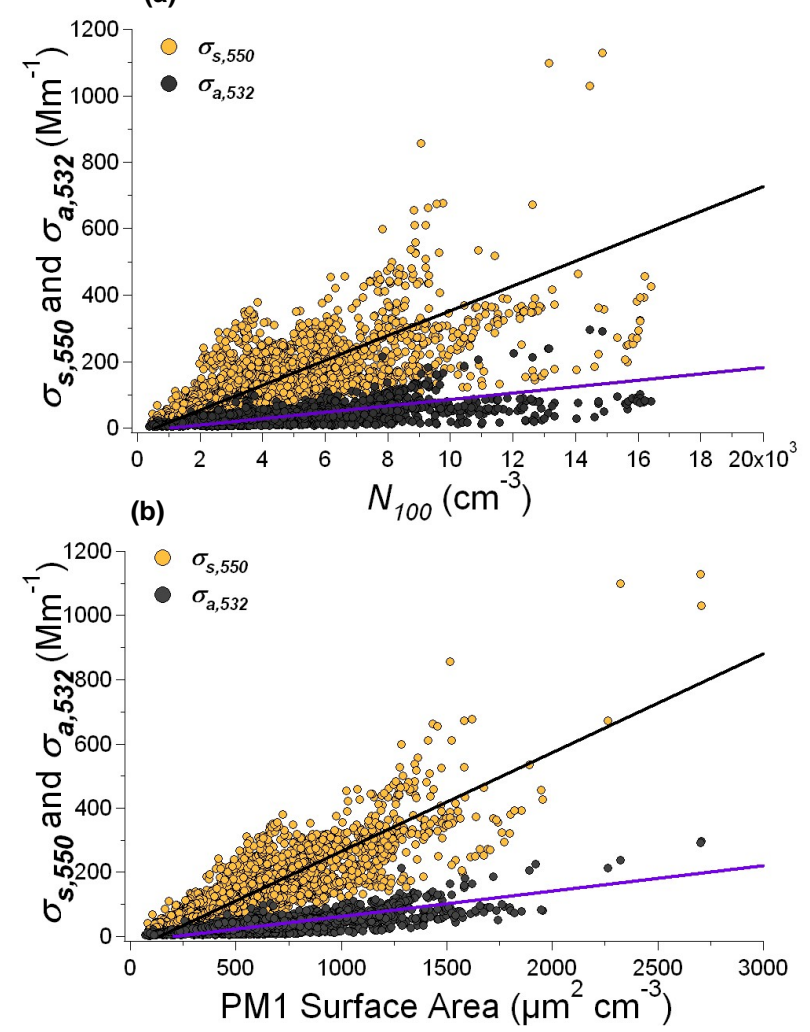

(c)

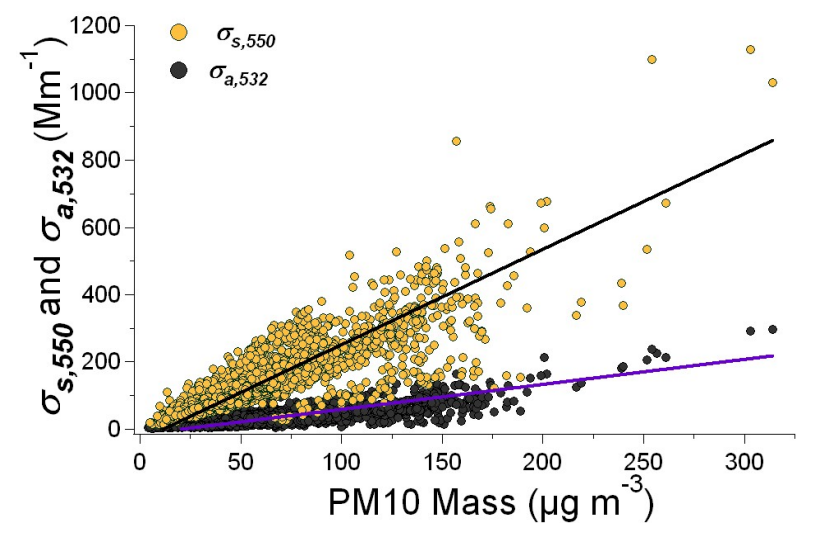

Fig. 13. Correlation between absorption and scattering coefficients and particle number, surface and mass concentrations: (a) black line: $y=(0.0376 \pm 0.0057) \mathrm{x}-20.59, R^{2}=0.48, n=2382$; purple line: $y=(0.00965 \pm 0.00015) \mathrm{x}-10.16, \quad R^{2}=0.42, \quad n=2400$; (b) black line: $y=(0.308 \pm 0.00033) \mathrm{x}-42.48, R^{2}=0.70, n=2580$; purple line: $y=(0.079 \pm 0.0010) \mathrm{x}-16.36, R^{2}=0.59, n=2563$; (c) black line: $y=(2.84 \pm 0.037) \mathrm{x}-32.8, R^{2}=0.66, n=2033$; purple line: $y=(0.742 \pm 0.009) \mathrm{x}-32.75, R^{2}=0.65, n=2136$.

derived from the fit lines are higher than the arithmetic mean values but within the standard deviations calculated from the individual data points $\left(\alpha_{s, \mathrm{PM}_{10}}=2.41 \pm 0.79 \mathrm{~m}^{2} \mathrm{~g}^{-1}\right.$, $\left.\alpha_{a, \mathrm{PM}_{10}}=0.52 \pm 0.22 \mathrm{~m}^{2} \mathrm{~g}^{-1}\right)$. The mass scattering and ab- sorption efficiencies obtained for $\mathrm{PM}_{1}$ from RMA fit lines in a correlation plot (not shown; $R^{2}=0.85, n=2033$ for $\sigma_{s, 550}$; $R^{2}=0.78, n=2136$ for $\left.\sigma_{a, 532}\right)$ were $\sim 50 \%$ higher than those for $\mathrm{PM}_{10}: \alpha_{s, \mathrm{PM}_{1}}=4.13 \mathrm{~m}^{2} \mathrm{~g}^{-1}, \alpha_{a, \mathrm{PM}_{1}}=1.09 \mathrm{~m}^{2} \mathrm{~g}^{-1}$ (arithmetic mean values and standard deviations calculated from the individual data points: $\alpha_{s, \mathrm{PM}_{1}}=3.60 \pm 0.86 \mathrm{~m}^{2} \mathrm{~g}^{-1}$ and $\alpha_{a, \mathrm{PM}_{1}}=0.78 \pm 0.29 \mathrm{~m}^{2} \mathrm{~g}^{-1}$ ).

The observed $\alpha_{s}$ values are in the range of literature data that are characteristic for urban areas. The IPCC report (2001) recommends a value of $1.0-3.5 \mathrm{~m}^{2} \mathrm{~g}^{-1}$ for urban areas, depending on pollution levels and particle size distribution. Waggoner et al. (1981) found a similar range of 2.23$2.94 \mathrm{~m}^{2} \mathrm{~g}^{-1}\left(\mathrm{PM}_{3}\right)$ for a variety of cities in the United States. Bergin et al. (2001) reported a value $2.3-3.6 \mathrm{~m}^{2} \mathrm{~g}^{-1}\left(\mathrm{PM}_{10}\right)$ for Beijing aerosol. Adam et al. (2004) reported values of $0.365-2.05 \mathrm{~m}^{2} \mathrm{~g}^{-1}$ (total suspended particles, ambient $\mathrm{RH}$ ) for urban Baltimore.

\subsubsection{Relationship between single scattering albedo and particle diameter}

In principle, changes in $\omega_{532}$ can be driven not only by changes in particle composition as discussed above (proportion of scattering and absorbing components) but also by changes in particle size, which influence the scattering and absorption efficiency. To probe the impact of changes in particle size, Fig. 14 displays $\omega_{532}$ plotted against the effective number mode diameter, which was determined by a monomodal lognormal fit to the measured particle number size distributions. Clearly, the $\omega_{532}$ values are not well correlated with the effective number mode diameter $\left(R^{2}=0.064\right.$ for all points, $(n=2831) R^{2}=0.0072$ when excluding $23-25$ July $(n=2414)$ ), nor with the effective surface or volume mode diameters determined by mono-modal lognormal fits to the submicron particle surface area and volume size distributions (not shown, $R^{2}=0.055(n=2836)$ and $R^{2}=0.012(n=2836)$, respectively). This indicates that the changes in $\omega_{532}$ were not primarily driven by changes in particle diameter, but rather by changes in particle composition.

During the "intense smoky" period both $\omega_{532}$ and the effective number mode diameter were on average larger than during rest of the campaign, which is consistent with previous studies of biomass burning aerosol (characteristic number mode diameters of fresh smoke: 100-180 nm; (Reid et al., 2005 and references therein)). Note, that while in general the particles during this time were larger, there was again no strong relation between size and $\omega_{532}\left(\omega_{532}=0.69-0.97\right.$ for number mode diameters $>120 \mathrm{~nm}$ ). Thus, particle composition rather than particle size seems to have driven changes in $\omega_{532}$ also during the biomass burning event.

\subsection{3 Ångström exponent and curvature}

The Ångström exponent $\stackrel{\circ}{a}_{s}$ ) is a parameter that is easily obtained through a variety of techniques, i.e., nephelometry, 


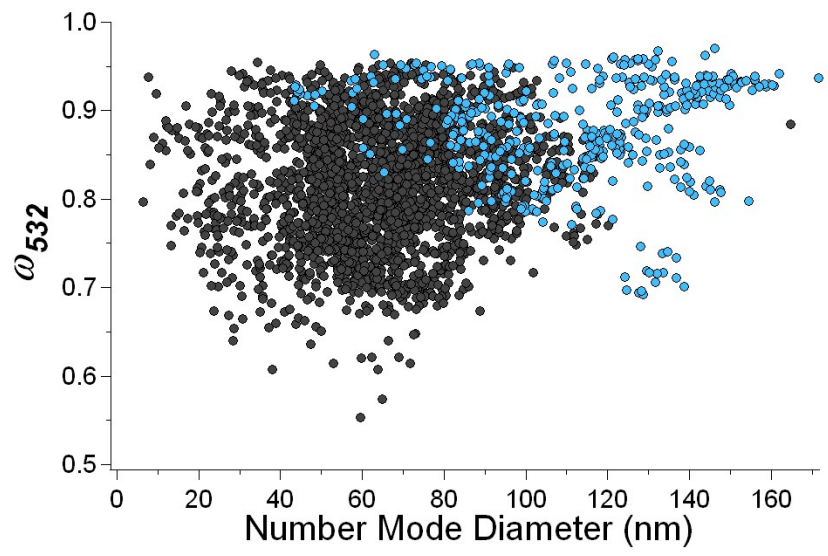

Fig. 14. Single scattering albedo $\left(\omega_{532}\right)$ vs. effective number mode diameter (mono-modal fit to particle number size distribution). The blue dots highlight the "intense smoky" period of 23-25 July.

sun photometry and satellite retrievals (e.g., Nakajima and Higurashi, 1998; Eck et al., 1999; Carrico et al., 2003; Quinn and Bates, 2005) As such, it is useful to use $\stackrel{\circ}{a}_{s}$ to elucidate other, more difficult to measure, parameters. Many studies have used the wavelength dependence of $\stackrel{a}{a}$ to gain information on the size distribution of the particles (e.g. Eck et al., 1999; Eck et al., 2001; O'Neill et al., 2001; Schuster et al., 2006; Gobbi et al., 2007). Many of these studies did not have direct measurements of the aerosol size distribution, but rather used retrievals from sun photometers (Eck et al., 1999; Eck et al., 2001). In this measurement campaign, optical and size distribution measurements were obtained from the same inlet. To our knowledge, this is the first study to quantify the Ångström curvature with simultaneous nephelometer and size distribution measurements.

Figure 2 displays the $\log \left(\sigma_{s} / \mathrm{Mm}^{-1}\right)$ vs. $\log (\lambda / \mathrm{nm})$ plots for 18 July, a relatively clean day, and 25 July 2006, during the local biomass burning event ("intense smoky" period). The dotted line is a linear fit, which fits the data adequately on the clean day, and the solid line is a secondorder polynomial (King and Byrne, 1976) which captures the curvature observed on the smoky day. This curvature leads to different calculated $\stackrel{\circ}{a}_{s}$ from Eq. (2) for different wavelength pairs. For example, the daily averages for 25 July were $1.36 \pm 0.07 \stackrel{\circ}{a}_{s}(550 / 700), \quad 1.21 \pm 0.07 \stackrel{\circ}{a}_{s}(450 / 700)$ and $1.03 \pm 0.07 \stackrel{\circ}{a}_{s}(450 / 550)$. Figure 15 displays the time series of $\stackrel{\circ}{a}_{s}$ for two different wavelength pairs, $\stackrel{\circ}{a}_{s}(550 / 700)$ and $\stackrel{\circ}{a}_{S}(450 / 550)$. While these values are very similar for some periods, they are different for others. The difference between these $\stackrel{\circ}{a}_{s}$ values is expressed by the first derivative of $\stackrel{\circ}{a}_{S}$ $\left(\stackrel{\circ}{a}_{s}^{\prime}\left(\lambda_{550}\right)\right)$, which is the second derivative of $\log \left(\sigma_{s} / \mathrm{Mm}^{-1}\right)$ vs. $\log (\lambda / \mathrm{nm})$ calculated according to Eq. (3) (Li et al., 1993; Eck et al., 1999); throughout this discussion $\stackrel{\circ}{s}_{S}^{\prime}\left(\lambda_{550}\right)$ will be referred to as the "second derivative".

The second derivative describes the curvature in the $\log \left(\sigma_{s} / \mathrm{Mm}^{-1}\right)$ vs. $\log (\lambda / \mathrm{nm})$ plot. For example, Fig. 2 il-

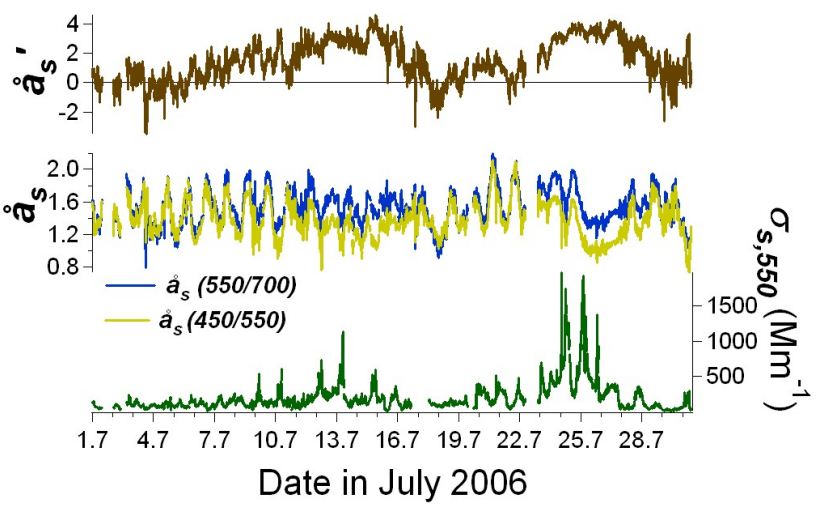

Fig. 15. Time series for second derivative $\left(\stackrel{\circ}{a}_{S}^{\prime}\right)$, Ångström exponent $\left(\stackrel{\circ}{a}_{s}\right)$ and total scattering coefficient $\left(\sigma_{s, 550}\right)$.

lustrates a positive curvature in the 25 July data corresponding to $\stackrel{\circ}{a}_{s}^{\prime}=3.44 \pm 0.26$. Almost no curvature was seen on 18 July $\left.\stackrel{\circ}{a}_{s}^{\prime}=-0.040 \pm 0.71\right)$. The campaign average of $\stackrel{\circ}{a}_{s}^{\prime}$ is $1.54 \pm 1.40$, indicating that on average there was less curvature than during the highly polluted days. The second derivative value measured on 25 July is substantially larger than the second derivative values reported for biomass burning aerosol in Bolivia ( $\stackrel{a}{e}_{e}^{\prime}=2.09$; Eck et al., 1999) and in Zambia $\left(\stackrel{\circ}{a}_{e}^{\prime}<2.2\right.$; Eck et al., 2001). The campaign average is similar to values Eck et al. (1999) measured at an urban site in the eastern US (1.10 and 1.76).

However, the values reported for these other campaigns used extinction and not scattering coefficients. The differences between Ångström exponents and curvatures derived from scattering and extinction measurements have been tested as described in Sect. 2.3.1. For 25 July, 18 July and for the entire campaign, the average second derivative values referring to extinction $\left(\stackrel{\circ}{a}_{e}^{\prime}\right)$ are $2.56 \pm 0.37,-0.044 \pm 0.54$ and $1.06 \pm 1.07$, respectively, when absorption is assumed to be proportional to $\lambda^{-1}$. Assuming a $\lambda^{-2}$ dependence of absorption yields only slightly different values $(2.50 \pm 0.39$, $-0.12 \pm 0.63$ and $1.07 \pm 1.10$, respectively). After accounting for absorption effects, the values of 25 July are still higher than the values reported from other biomass burning events, but the relative differences are reduced (10-20\% instead of $50-70 \%$ ). Overall, the second derivative values referring to extinction were about $30 \%$ lower than those referring to the scattering coefficient.

The time series of $\sigma_{s, 550}$ was also included in Fig. 15 to highlight the polluted periods. As seen from Fig. 15, the second derivative has non-zero values around the more polluted periods (i.e., 12-13 July 2006 and 23-25 July 2006), though the second derivative is non-zero for longer periods than just during the periods with increased pollution. This suggests that the driving force for the curvature is not only the pollution level. Figure 16 displays the dependence of the second derivative on pollution level, represented here by total scattering. At lower scattering values $\left(<500 \mathrm{Mm}^{-1}\right)$, the second 


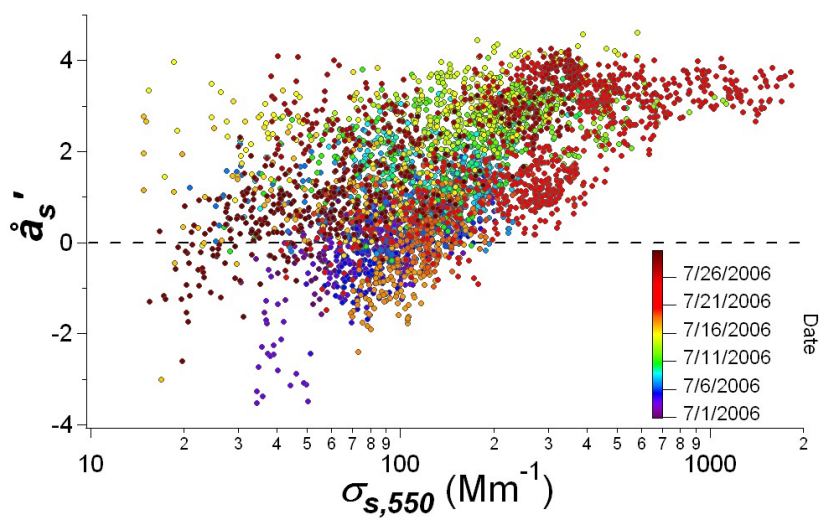

Fig. 16. Second derivative $\left(\stackrel{\circ}{a}_{s}^{\prime}\right)$ versus scattering coefficient $\left(\sigma_{s, 550}\right)$ for the whole campaign, including 23-25 July.

(a)
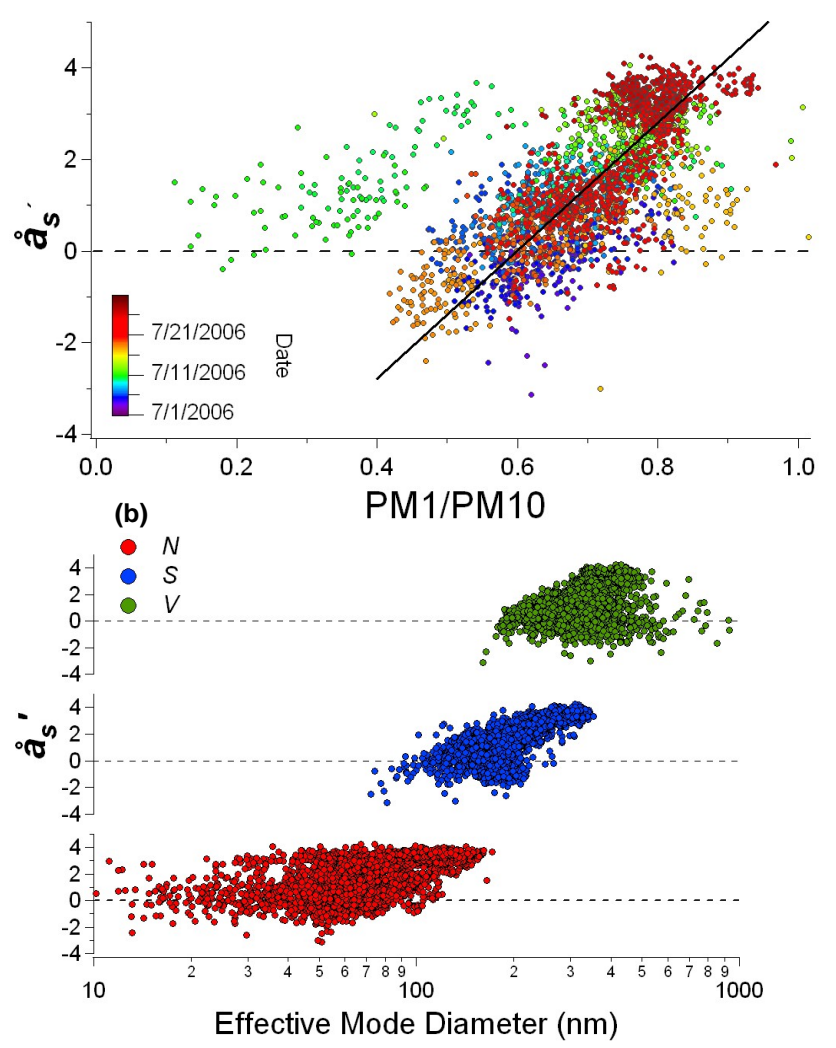

Fig. 17. Second derivative $\left(\stackrel{\leftrightarrow}{a}_{s}^{\prime}\right)$ vs. (A) $\mathrm{PM}_{1} / \mathrm{PM}_{10}$ mass ratio derived from size distribution measurements (black line RMA fit, $\mathrm{y}=14.00 \mathrm{x}-8.39, R^{2}=0.53, n=2343$, excluding 10 July outliers) and (B) effective mode diameter from mono-modal lognormal fit to measured submicron size distributions of particle number (red dots), surface area (blue dots) and volume (green dots) for the whole campaign, including 23-25 July. derivative tends to increase dramatically with increasing scattering, while almost constant values for the second derivative of $\sim 3.5$ occurred for $\sigma_{s, 550}>500 \mathrm{Mm}^{-1}$.

Using other ground based techniques (i.e., sun photometers) it has been suggested that the main driving force of the curvature is the fine/coarse ratio of the size distribution as well as the diameter of the fine mode particles (e.g., Eck et al., 1999; Schuster et al., 2006; Gobbi et al., 2007). Figure 17a displays the second derivative as a function of the submicron aerosol fraction (fine $D_{p}<1 \mu \mathrm{m}$ ). All of the campaign data is included in this graph, including 23-25 July. The data are color coded for the day of measurement. Generally, there is an increase in the second derivative with an increase in fine fraction. Additionally, all of the data except 10 July (the green points to the left of the majority of the data) have a very similar relationship between the second derivative and fine fraction; for these days, the curvature in $\stackrel{\circ}{a}_{s}$ can be explained by an increase in the fine fraction. On 10 July there was a greater increase in the $\mathrm{PM}_{10}$ mass than in the $\mathrm{PM}_{1}$ mass and thus the $\mathrm{PM}_{1} / \mathrm{PM}_{10}$ fraction is the lowest in this campaign. It is currently not clear what caused this exceptional increase in $\mathrm{PM}_{10}$ mass; a measurement artifact cannot be excluded, but we have no other evidence for it. The black line in Fig. 17a is a reduced major axis (RMA) fit $(y=14.00 x-$ $\left.8.39 ; R^{2}=0.53(n=2343)\right)$ with the 10 July data excluded. Figure $17 \mathrm{~b}$ displays the second derivative versus the effective mode diameters from mono-modal lognormal fits to the submicron size distributions of particle number, surface area and volume. The RMA fits (not shown) are, for the number mode diameter: $\mathrm{y}=0.0498 \mathrm{x}-2.11, R^{2}=0.22 \quad(n=3002)$; for the surface mode diameter: $\mathrm{y}=0.0264 \mathrm{x}-3.8075, R^{2}=0.57$ $(n=3007)$ and for the volume mode diameter: $\mathrm{y}=0.0167 \mathrm{x}-$ $4.33, R^{2}=0.054(n=2998)$. Only the surface mode diameter is similarly well correlated with $\stackrel{\circ}{a}_{s}^{\prime}$ as the $\mathrm{PM}_{1} / \mathrm{PM}_{10}$ ratio. Thus, our in situ measurement data suggest that the fine/coarse particle mass ratio $\left(\mathrm{PM}_{1} / \mathrm{PM}_{10}\right)$ together with the fine particle surface size distribution drive the curvature in the Ångström exponent.

The Angström exponent, on the other hand, is best correlated with the volume size distribution as illustrated in Fig. 18. The RMA fits (not shown) are, for the number effective mode diameter: $\mathrm{y}=0.00805 \mathrm{x}+0.90, R^{2}=0.033$; the surface effective mode diameter: $\mathrm{y}=-0.00428 \mathrm{x}+2.31$, $R^{2}=0.10$ and for the volume effective mode diameter: $\mathrm{y}=-0.00269 \mathrm{x}+2.39, R^{2}=0.38 \quad(n=2990) . \quad$ In order to explore the relationship between the Ångström exponent, its curvature and the particle size distribution, and to compare with AERONET data analysis, the current study's data has been displayed in the formulation of Gobbi et al. (2007) (Fig. 19). In this formulation the Ångström difference $\left(\stackrel{\circ}{a}_{S}(450 / 550)-\stackrel{\circ}{a}_{s}(550 / 700)\right)$, which is similar to Ångström curvature, is plotted against the Ångström exponent $\left(\stackrel{\circ}{a}_{S}(450 / 550)\right)$ to infer the radius of the aerosol fine mode $\left(R_{f}\right)$ together with percentage of the fine mode that contributes to total extinction. This representation was designed 


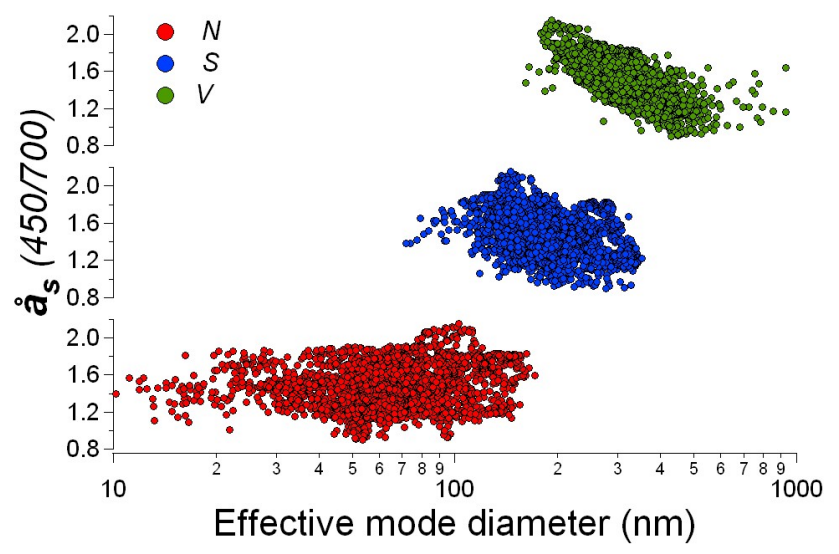

Fig. 18. Ångström exponent $\left(\stackrel{\circ}{a}_{S}\right)$ vs. the effective mode diameter from mono-modal lognormal fit to measured submicron size distributions of particle number (red dots), surface area (blue dots) and volume (green dots).

for AERONET data with examples of data from various regions (such as Beijing and Alta Floresta Brazil) (Gobbi et al., 2007), and as such, the formulation was designed for sun photometer measurements of aerosol optical thickness, and not for ground-based measurements of dry scattering coefficients. Nevertheless, the data from the current campaign are similar to the "Polluted Beijing" AERONET data shown in Gobbi et al. (2007). The data from this current campaign fall into the range of $\sim 40-90 \%$ fine mode fraction (Fig. 19a), which is similar to the range of $\mathrm{PM}_{1} / \mathrm{PM}_{10}$ ratios derived from the TDMPS+APS size distribution measurements and shown in Fig. 17a. In Fig. 19b the data are color coded for the $\mathrm{PM}_{1} / \mathrm{PM}_{10}$ mass ratio. The measurement-based $\mathrm{PM}_{1} / \mathrm{PM}_{10}$ mass ratios are consistent with the trend of the percentage contribution of the fine mode to total extinction predicted by the formalism of Gobbi et al. (2007). The data with a higher $\mathrm{PM}_{1} / \mathrm{PM}_{10}$ ratio ( $\sim 0.8$; red dots in Fig. $\left.19 \mathrm{~b}\right)$ are at the bottom where the fine particles should contribute more to the total extinction ( 70-90\%), and the data with lower $\mathrm{PM}_{1} / \mathrm{PM}_{10}$ ratio ( $\sim 0.5$ blue dots in Fig. $19 \mathrm{~b})$ are at the top where the fine particles should contribute less $(\sim 50-60 \%)$. The highly polluted days of 23-25 July are in the bottom left corner of Fig. 19a (fine mode percentage 70-90\%; $R_{f}=0.12-0.2 \mu \mathrm{m}$ ), which indicates that during these days the proportion and the size of the fine mode particles were larger than on average, which is consistent with the TDMPS+APS size distribution measurements. Gobbi et al. (2007) had not stated which type of size distribution was used in their formalism, but the campaign average mode diameters of the surface area and volume size distributions in Fig. 12 ( $D_{p} \approx 250 \mathrm{~nm}$, and $362 \mathrm{~nm}$, respectively) are near the middle of the range of particle sizes indicated by the data points in Fig. 19 $\left(R_{f} \approx 80-200 \mathrm{~nm}\right)$. Only the volume mode diameter, however, followed the trend of $R_{f}$ in the formulation of Gobbi et al. (2007), where particles size increases from right to (a)
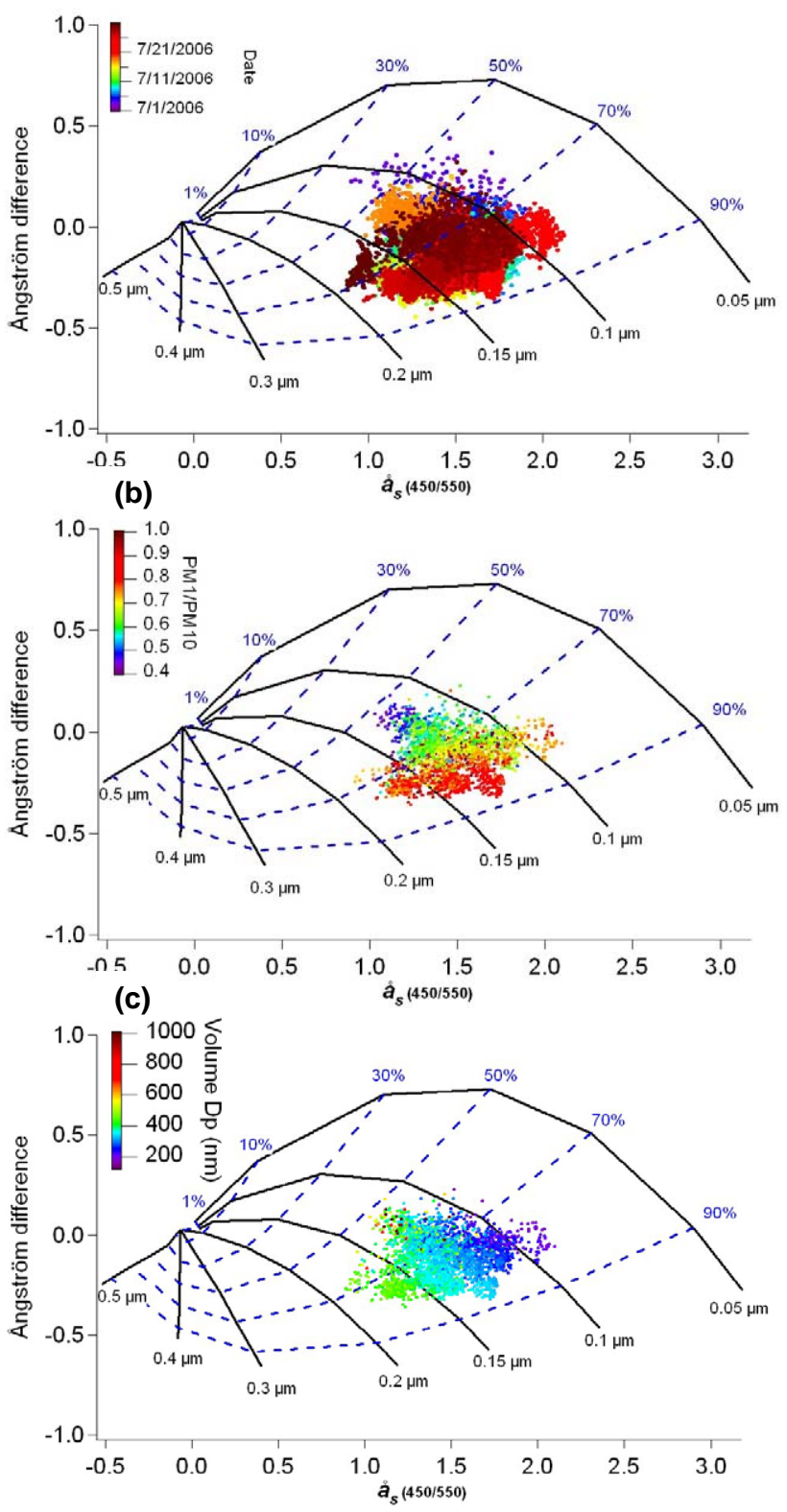

Fig. 19. Data analysis according to the remote sensing formalism of Gobbi et al. (2007): Ångström difference $\left(\stackrel{\circ}{a}_{S}(450 / 550)-\stackrel{\circ}{a}_{S}(550 / 700)\right)$ versus Ångström exponent $\left(\stackrel{\circ}{a}_{S}(450 / 550)\right)$. The black lines represent the fine mode modal radii $\left(R_{f}\right)$ and the dotted blue lines represent the percentage contribution of the fine mode to total extinction. The points are data from the current study color coded as (a) date; (b) $\mathrm{PM}_{1} / \mathrm{PM}_{10}$ mass ratio; (c) effective volume mode diameter (mono-modal fit to particle volume size distribution). 


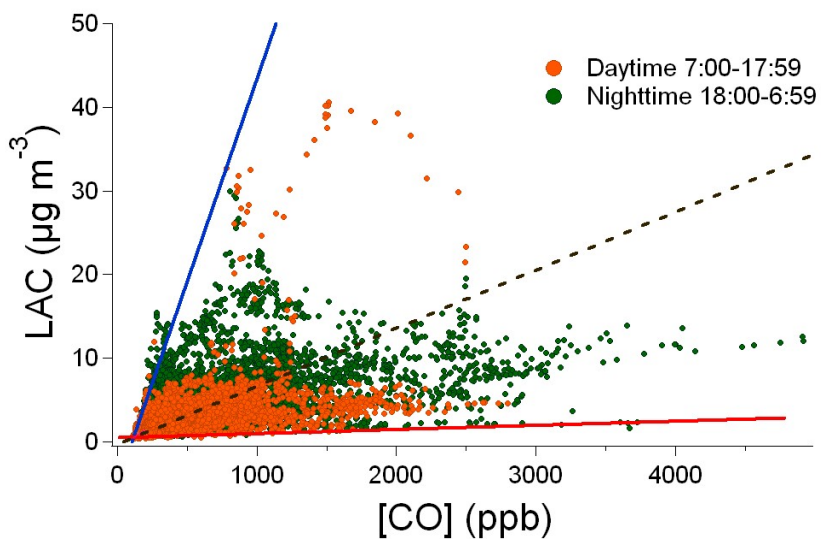

Fig. 20. Light absorbing carbon (LAC) mass concentration versus carbon monoxide mixing ratio. Each point is a two-minute averaged data point. The dotted black line is the reduced major axis best fit ( $\left.\mathrm{y}=0.00694 \mathrm{x}-0.278 ; R^{2}=0.18, n=7945\right)$ and the blue and red solid lines represent upper and lower boundary conditions ( $y=0.0485 x-5.17 ; y=0.000498 x+0.496$, respectively).

left as illustrated by the color coding of the data points in Fig. 19c; neither the surface nor the number mode diameters followed this trend (data not shown). Quantitatively, the $R_{f}$ values matched well with small effective volume mode diameters (purple dots, $R_{f} \approx 0.1 \mu \mathrm{m}, D_{p} \approx 200 \mathrm{~nm}$ ), but not so well with larger mode diameters (green dots, $R_{f} \approx 0.15 \mu \mathrm{m}, D_{p} \approx 400 \mathrm{~nm}$ ). We calculated also Ångström exponents and differences for extinction as described in Sect. 2.3.1 $\left(\stackrel{\circ}{a}_{e}(450 / 550), \stackrel{\circ}{a}_{e}(450 / 550)-\stackrel{\circ}{a}_{e}(550 / 700)\right)$ and inserted these into the formulation (not shown). However, the value ranges were similar and differences between scattering and extinction data did not explain the systematic deviations between the observed mode diameters and the $R_{f}$ values inferred from the optical parameters. Thus, we suggest that more data sets from in situ measurements of aerosol optical parameters and particle size distributions should be used to evaluate formalisms applied in aerosol remote sensing.

\subsection{Correlation of light absorbing carbon and carbon} monoxide

The absorption coefficient $\left(\sigma_{a}\right)$ is a measure of the amount of light absorbing material in the aerosol. In general, this material is composed of carbon containing compounds that are referred to as light absorbing carbon (LAC) or black carbon (BC) (Andreae and Gelencser, 2006; Bergstrom et al., 2007), but mineral components, such as those contained in desert dust, may also contribute to aerosol absorption (Jennings et al., 1996; Fialho et al., 2005; Derimian et al., 2008). In the following discussion it will be assumed that the absorption coefficient was dictated by the LAC concentration with a single mass absorption efficiency value of $7.5 \mathrm{~m}^{2} \mathrm{~g}^{-1}$, which refers to uncoated, fully graphitized soot (Bond, 2006). Therefore the calculated LAC concentration should be considered as an equivalent parameter and approximate lower limit estimate for the actual concentration of light absorbing carbonaceous aerosol components.

A major source of LAC is combustion of fossil fuels and biomass, during which both LAC and $\mathrm{CO}$ are released. Consequently, strong correlations between LAC mass and [CO] have been seen in other urban areas (Chen et al., 2001; Baumgardner, 2002; Lim, 2002; Park, 2005; Kondo et al., 2006; Baumgardner, 2007), although in these studies instrumentation other than the PAS were used, and thus the Elemental Carbon (EC) mass was reported. Since the ratio of LAC mass to [CO] is highly dependent upon many factors including the type and proximity of combustion source, combustion conditions and the presence of dust, these previous studies have found the ratio to differ significantly between cities and seasons (Chen et al., 2001; Baumgardner, 2002; Lim, 2002; Park, 2005; Kondo et al., 2006; Baumgardner, 2007).

Figure 20 displays the correlation between LAC mass and [CO] obtained for this study. The $\triangle \mathrm{LAC} / \Delta \mathrm{CO}$ values were calculated as described in Kondo et al. (2006). The background $\mathrm{LAC}$ and $\mathrm{CO}$ levels, $\mathrm{LAC}_{0}$ and $\mathrm{CO}_{0}$, were assumed to be the 1.25th percentile value and the $\Delta \mathrm{LAC} / \Delta \mathrm{CO}$ values were calculated in three ways;

1. the slope of LAC mass vs. [CO] reduced major axis linear fit (Fig. 20);

2. the slope of a linear fit, forced through zero, of LAC$\mathrm{LAC}_{0}$ vs. $\mathrm{CO}-\mathrm{CO}_{0}$;

3. the median value of $\left(\mathrm{LAC}-\mathrm{LAC}_{0}\right) /\left(\mathrm{CO}-\mathrm{CO}_{0}\right)$ with all values where $\mathrm{CO}-\mathrm{CO}_{0}<100 \mathrm{ppb}$ excluded.

The three methods produced $\triangle \mathrm{LAC} / \triangle \mathrm{CO}$ values of $6.94 \pm 0.07 \mathrm{ng} \mathrm{m}^{-3} \mathrm{ppb}^{-1}, \quad 4.96 \pm 0.05 \mathrm{ng} \mathrm{m}^{-3} \mathrm{ppb}^{-1}$ and $6.45 \pm 9.21 \mathrm{ng} \mathrm{m}^{-3} \mathrm{ppb}^{-1}$, respectively. These values are similar to values measured in Guangzhou during the PRIDEPRD2004 campaign (7.9 $\pm 0.5 \mathrm{ng} \mathrm{m}^{-3} \mathrm{ppb}^{-1}$ ) (Andreae et al., 2008) as well as in the Japanese cities of Nagoya $\left(6.3 \pm 0.5 \mathrm{ng} \mathrm{m}^{-3} \mathrm{ppb}^{-1}\right)$ and Tokyo $\left(5.7 \pm 0.9 \mathrm{ng} \mathrm{m}^{-3} \mathrm{ppb}^{-1}\right)$ (Kondo et al., 2006). Much smaller values were measured in Mexico City (1.63-2.23 $\mathrm{ng} \mathrm{m}^{-3} \mathrm{ppb}^{-1}$ ) (Baumgardner, 2002; Jiang et al., 2005; Baumgardner, 2007), Baltimore $\left(2.3 \pm 0.8 \mathrm{ng} \mathrm{m}^{-3} \mathrm{ppb}^{-1}\right)$ (Park, 2005) and Atlanta (3.2 $\mathrm{ng} \mathrm{m}^{-3} \mathrm{ppb}^{-1}$ ) (Lim, 2002). Additionally, smaller values were also measured in the fall, winter and spring months in Fort Meade, Maryland $2.7 \mathrm{ng} \mathrm{m}^{-3} \mathrm{ppb}^{-1}$, $2.9 \mathrm{ng} \mathrm{m}^{-3} \mathrm{ppb}^{-1}$ and $2.7 \mathrm{ng} \mathrm{m}^{-3} \mathrm{ppb}^{-1}$, respectively, though similar values to this study were measured there in the summer (4.1-6.7 $\mathrm{ng} \mathrm{m}^{-3} \mathrm{ppb}^{-1}$ ) (Chen et al., 2001).

Figure 20 displays the uncorrected LAC mass vs. [CO] data with the reduced major axis fit and boundary conditions. The slopes of the lines shown in Fig. $20(\Delta \mathrm{LAC} / \Delta \mathrm{CO})$ range from 0.498 to $48.5 \mathrm{ng} \mathrm{m}^{-3} \mathrm{ppb}^{-1}$. No study, to 
our knowledge, has reported as high values as our upper boundary, $48.5 \mathrm{ng} \mathrm{m}^{-3} \mathrm{ppb}^{-1}$ and even the averages reported above are among the higher values measured. In order to determine whether unique conditions were causing these high values, the time and day when $\Delta \mathrm{LAC} / \Delta \mathrm{CO}$ was greater than $8 \mathrm{ng} \mathrm{m}^{-3} \mathrm{ppb}^{-1}$ were noted. $65 \%$ of the values over $8 \mathrm{ng} \mathrm{m}^{-3} \mathrm{ppb}^{-1}$ occurred during the nighttime (18:0007:00), with $77 \%$ of these high nighttime values occurring either in the early morning (04:00-6:59) or evening (19:0021:59), close to the times of highest truck traffic in the region. These values were present on every day where both $\mathrm{CO}$ and $\mathrm{LAC}$ were measured, thus these high $\triangle \mathrm{LAC} / \Delta \mathrm{CO}$ events are not unusual for this area, but a daily occurrence. These values could be produced through relatively efficient combustion with low CO concentrations and high emissions of LAC. Additionally, the high $\triangle \mathrm{LAC} / \triangle \mathrm{CO}$ values could be due to absorption enhancement (higher LAC absorption efficiency) as was observed for coated versus uncoated soot particles (Saathoff et al., 2003) or to non-combustion sources of light absorbing particulate matter. The large range of $\Delta \mathrm{LAC} / \Delta \mathrm{CO}$ values measured during this campaign suggests a variety of sources for both absorbing aerosols and CO in the PRD region.

\subsection{Radiative Forcing Sensitivities}

By scattering and absorbing incoming solar radiation, aerosols can impact the radiative balance and cool the surface of the Earth. The cooling potential of aerosol particles generally increases with increasing single scattering albedo and backscattering fraction.

Figure 21 displays $\omega_{532}$ vs. $b_{550}$ for this campaign (including 23-25 July) with the color scale as local date. There are three lines on the graph to describe an upper and lower boundary as well as a fit through the bulk of the data. The black line is a fit forced through the data point with the highest $\omega_{532}$ and lowest $b_{550}$ to capture the bulk of the data as well as the data with high $\omega_{532}$. The blue and red lines are not fits through the data, but rather represent the approximate boundaries of the data. The data that are clustered at the top left hand side of the graph, where the lines meet, were all measured during the day on 25 July ( 10:00-17:00) which is during the biomass burning event. Additionally, as can be seen by the color coding in Fig. 21, the colors are not distributed evenly, but rather each time period has its own relationship between $\omega_{532}$ and $b_{550}$. For this reason we have chosen the two boundary conditions and the middle fit to test the sensitivity of radiative forcing on various $\omega_{532}$ vs. $b_{550}$ trends; hence, the lines are not meant to describe the whole data set, but rather describe the range of realistic $\omega_{532}$ vs. $b_{550}$ conditions.

Since $\omega_{532}$ and $b_{550}$ are negatively correlated (Fig. 21), they partially offset their respective radiative forcing. This negative correlation has been previously noted in Reid and

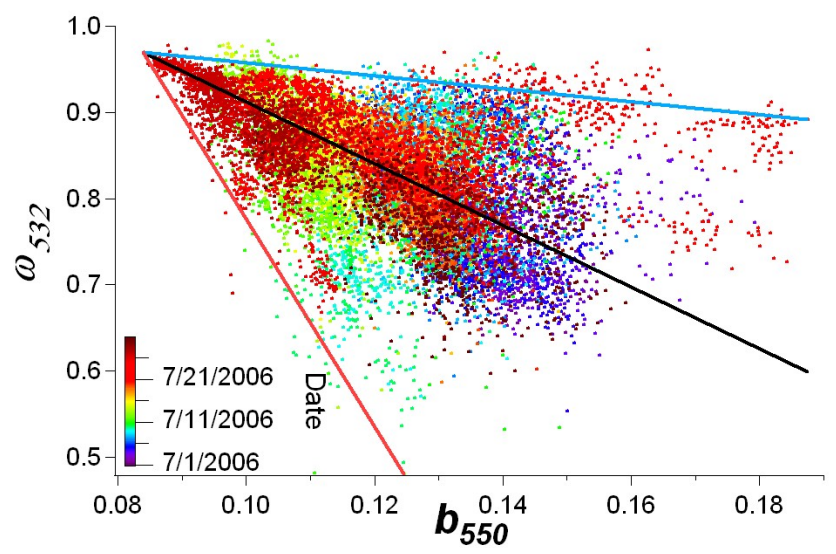

Fig. 21. Single scattering albedo $(532 \mathrm{~nm})$ vs. backscattering fraction $(550 \mathrm{~nm})$ for the whole campaign, including 23-25 July. The black line is a linear fit $\left(\mathrm{y}=-3.58 \mathrm{x}+1.27, R^{2}=0.22, n=15563\right)$ and the red and blue lines represent lower and upper boundaries, respectively $(\mathrm{y}=-12.07 \mathrm{x}+1.98, \mathrm{y}=-0.754 \mathrm{x}+1.03)$.

Hobbs (1998), however the impact of this relationship on radiative forcing was not discussed.

The radiative forcing equation from Haywood and Shine (1995) was used to investigate how this coupling may impact the aerosol particles' top of the atmosphere radiative forcing:

$$
\Delta F / \delta \approx-D S_{o} T_{\mathrm{atm}}^{2}\left(1-A_{c}\right) \omega \beta\left\{\left(1-R_{S}\right)^{2}-\left(2 R_{S} / \beta\right)[(1 / \omega)-1]\right\}
$$

The aerosol radiative forcing efficiency $(\Delta \mathrm{F} / \delta)$ is defined as the forcing per unit aerosol optical depth. In order to use Eq. (6) to test the sensitivity of the coupling of $\omega_{532}$ and $b_{550}$, the other terms in the equation were assumed to be constant and have the following values: fractional daylight $D=0.5$, solar flux $S_{o}=1370 \mathrm{~W} \mathrm{~m}^{-2}$, atmospheric transmission $T_{\mathrm{atm}}=0.76$, fractional cloud amount $A_{c}=0.6$, surface reflectance $R_{s}=0.15$. The upscatter fraction $\beta$ was calculated from $b_{550}$ using the parameterization of Wiscombe and Grams (1976) in Sheridan and Ogren (1999). These calculations are not meant to be a rigorous analysis of the radiative forcing of these particles, but rather only to test the sensitivity of the radiative forcing calculation to coupling the $b_{550}$ and $\omega_{532}$.

Figure 22a displays $\Delta \mathrm{F} / \delta$ as a function of $b_{550}$ for a variety of cases. The dotted lines represent constant $\omega_{532}$ values with varying $b_{550}$. The solid black line uses the fit for the black line in Fig. 21 to calculate $\omega_{532}$ from various $b_{550}$; thus, as the $b_{550}$ increases, this line models the $\omega_{532}$ values decreasing as seen by the black line in Fig. 21. The solid red and blue lines in Fig. 22 use their respective trends from Fig. 21 to couple $b_{550}$ and $\omega_{532}$. The limits of the solid lines in Fig. 22 correspond to the end points of the fit lines in Fig. 21. For example, in Figure 21 the red line ends at $b_{550}=0.13$ and thus the line on Fig. 22a does not go past $b_{550}=0.13$. 
(a)

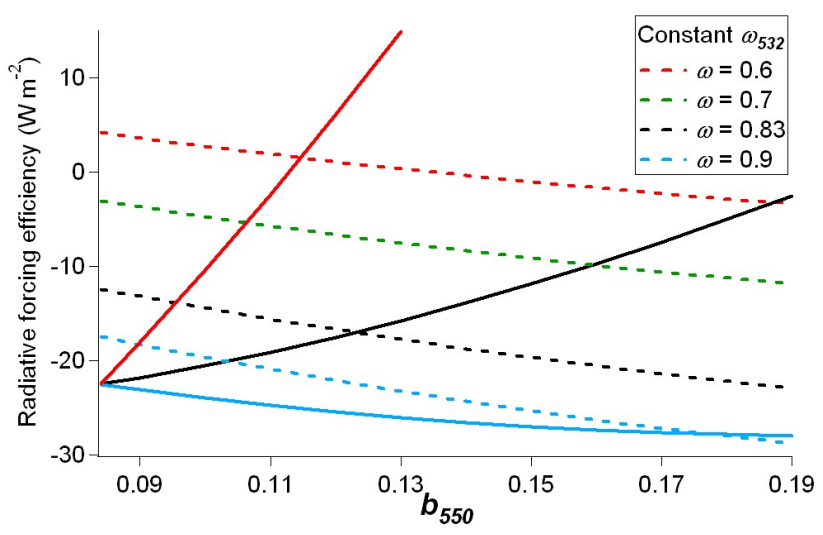

(b)

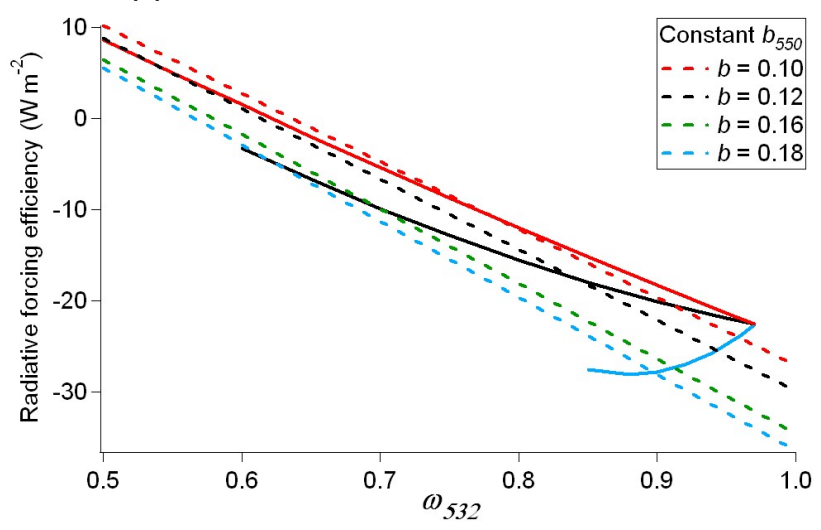

Fig. 22. Radiative forcing efficiency calculated from Eq. (6): (a) as a function of $b_{550}$ and (b) as a function of $\omega_{532}$. The dotted lines are based on constant $\omega_{532}$ or $b_{550}$ values, respectively. For the solid lines, $\omega_{532}$ was calculated as a function of $b_{550}$ using the fit (black line) or the boundary conditions (red and blue lines) from Fig. 21.

The dotted lines in Fig. 22a show that as $b_{550}$ increases, with a constant $\omega_{532}$, the forcing efficiency decreases nearlinearly, which indicates an increased cooling of the Earth's surface. Alternatively, as $\omega_{532}$ decreases, at a fixed $b_{550}$, the forcing efficiency increases, indicating increasing warming of the surface. If both $b_{550}$ and $\omega_{532}$ are allowed to vary together, a more complex relationship appears. For the red and black line, instead of decreasing the forcing efficiency, the forcing efficiency actually increases with $b_{550}$, indicating the single scattering albedo dominates the radiative forcing calculation. The blue line still shows decreasing forcing efficiency with increasing $b_{550}$, but the decrease is not as large as if $\omega_{532}$ were held constant.

Figure 22b displays $\Delta \mathrm{F} / \delta$ calculated as a function of $\omega_{532}$. The dotted lines show that at a constant $b_{550}$, the radiative forcing efficiency decreases linearly with increasing $\omega_{532}$, thus leading to increased cooling potential. The solid red and black lines still have this general trend, but the decrease in forcing efficiency with increasing $\omega_{532}$ is diminished, thus the cooling potential of the aerosols is less. It is evident from Fig. 22a and b that for these two cases, $\omega_{532}$ has a larger effect on radiative forcing than $b_{550}$. In contrast, for the upper boundary of the observed $\omega_{532}$ vs. $b_{550}$ range (blue line in Figs. 21 and 22), an increase in $\omega_{532}$ of 0.90 to 0.97 leads to an increase in radiative forcing efficiency indicating that in this case, changes in $b_{550}$ dominate the changes in overall forcing of the aerosol.

For the type of aerosol present in the PRD region, the expected increase in cooling potential with increasing $b_{550}$ is counteracted by the correlated decrease in the $\omega_{532}$, which results in the aerosols at higher $b_{550}$ having a smaller cooling potential. And the reduction in cooling with decreasing $\omega_{532}$ is less than expected because of the increase in $b_{550}$. This sensitivity test highlights the fact that the coupling of these parameters has the ability to greatly impact radiative forcing and should be considered when modeling the PRD region. Similar relations between $b_{550}$ and $\omega_{532}$ have been observed in a follow-up measurement campaign in the vicinity of Beijing (Garland et al., 2008 ${ }^{2}$ ), indicating that this may be a general feature of aerosols around highly polluted mega-cities.

\section{Conclusions}

The aerosol optical properties at a rural site in the Pearl River Delta were measured as a part of the PRIDE-PRD2006 campaign. Most of the parameters measured and calculated for this site are similar to those of urban areas, confirming the regional character of air pollution in the PRD. The observed extensive aerosol properties (scattering and absorption coefficients) were much more variable than the derived intensive properties (backscattering fraction, single scattering albedo and Ångström exponent). Both extensive and intensive properties were not greatly influenced by local wind direction, though differences in back trajectories were seen to influence the extensive properties and $\omega_{532}$. A majority of these trajectories $(\sim 80 \%)$ originated in the heavily populated PRD region $\left(90-180^{\circ}\right.$ from the measurement site).

Pronounced diurnal cycles were observed for $\omega_{532}, \stackrel{\circ}{a}_{s}, \sigma_{s}$ and $\sigma_{a}$. The $\sigma_{s}$ and $\sigma_{a}$ values increased at night as the nocturnal boundary layer formed while surface emissions continued, and then decreased during the day due to mixing with the overlying residual layer. The diurnal variation of $\omega_{532}$ was also consistent with such mixing and no evidence was found to indicate strong local production of secondary aerosol mass in spite of a highly photochemically active environment. Only a minor increase in scattering material during

\footnotetext{
${ }^{2}$ Garland, R. M., Schmid, O., Nowak, A., Achtert, P., Wiedensohler, A., Gunthe, S. S., Takegawa, N., Kita, K., Kondo, Y., Hu, M., Shao, M., Zeng, L. M., Zhu, T., Andreae, M. O., and Pöschl, U.: Aerosol optical properties observed during CAREBeijing-2006: characteristic differences between the inflow and outflow of Beijing city air, J. Geophys. Res.-Atmos., submitted, 2008.
} 
the afternoon could be attributed to processes other than mixing. The diurnal cycle of $\stackrel{\circ}{a}_{s}$ indicates smaller particles in the afternoon, which may be due to new particle formation or temperature-related changes in the gas-particle partitioning of semi-volatile aerosol components.

Low values of single scattering albedos indicate strong emissions of light absorbing carbon, and highly variable ratios of LAC to CO concentration imply a complex mix of combustion sources. Enhanced nighttime levels of LAC appear to be due to diesel soot emissions from regulated truck traffic in the late evening and early morning.

The Ångström exponent exhibited a wavelength dependence (curvature) that was related to the ratio of fine and coarse particle mass $\left(\mathrm{PM}_{1} / \mathrm{PM}_{10}\right)$ as well as the modal diameter of the fine particle surface distribution. The results indicate consistency between the in situ measurements and a remote sensing formalism for the estimation of fine particle fraction and modal diameter, but they also revealed systematic deviations. Test calculations and comparisons with earlier studies confirm the consistency of Ångström exponent and curvature values derived from scattering and extinction data. Thus we suggest that more data sets from in situ measurements of aerosol optical parameters and particle size distributions should be used to evaluate formalisms applied in aerosol remote sensing.

Last but not least, the single scattering albedo and the backscattering fraction of the investigated aerosols exhibited a negative correlation, which influences the calculation of radiative forcing sensitivity and can be important for the modeling of the radiative balance in this region and around other highly polluted mega-cities.

Acknowledgements. The PRIDE-PRD2006 campaign was sponsored by the China National Basic Research and Development Program (2002CB410801 and 2002CB211605). This study was supported by the Max Planck Society (MPG), the Leibniz Institute for Tropospheric Research (IfT), the University of Tokyo (UT), and Peking University (PKU). Thanks to all team members for support during the campaign and fruitful discussions afterwards, to B. Mamtimin for preparing the population density map, to Y. F. Cheng for help in calculating uncertainty estimates and to S. Gunthe for help at the end of the campaign. The authors gratefully acknowledge the NOAA Air Resources Laboratory (ARL) for the provision of the HYSPLIT transport and dispersion model used in this publication. Thanks to the referees and editor of this paper for helpful and stimulating comments.

Edited by: C. Chan

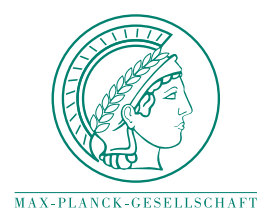

The publication of this article is financed by the Max Planck Society.

\section{References}

Adam, M., Pahlow, M., Kovalev, V. A., Ondov, J. M., Parlange, M. B., and Nair, N.: Aerosol optical characterization by nephelometer and lidar: the Baltimore Supersite experiment during the Canadian forest fire smoke intrusion, J. Geophys. Res.-Atmos., 109, D16S02, doi:10.1029/2003JD004047 ,2004.

Anderson, T. L., Covert, D. S., Marshall, S. F., Laucks, M. L., Charlson, R. J., Waggoner, A. P., Ogren, J. A., Caldow, R., Holm, R. L., Quant, F. R., Sem, G. J., Wiedensohler, A., Ahlquist, N. A., and Bates, T. S.: Performance characteristics of a high-sensitivity, three-wavelength, total scatter/backscatter nephelometer, J. Atmos. Ocean. Tech., 13, 967-986, 1996.

Anderson, T. L., Covert, D. S., Wheeler, J. D., Harris, J. M., Perry, K. D., Trost, B. E., Jaffe, D. J., and Ogren, J. A.: Aerosol backscatter fraction and single scattering albedo: measured values and uncertainties at a coastal station in the Pacific Northwest, J. Geophys. Res.-Atmos., 104, 26 793-26 807, 1999.

Anderson, T. L., Masonis, S. J., Covert, D. S., Ahlquist, N. C., Howell, S. G., Clarke, A. D., and McNaughton, C. S.: Variability of aerosol optical properties derived from in situ aircraft measurements during ACE-Asia, J. Geophys. Res.-Atmos., 108, 8647, doi:10.1029/2002JD003247, 2003.

Anderson, T. L. and Ogren, J. A.: Determining aerosol radiative properties using the TSI 3563 integrating nephelometer, Aerosol Sci. Tech., 29, 57-69, 1998.

Andreae, M. O. and Gelencser, A.: Black carbon or brown carbon? The nature of light-absorbing carbonaceous aerosols, Atmos. Chem. Phys., 6, 3131-3148, 2006, http://www.atmos-chem-phys.net/6/3131/2006/.

Andreae, M. O., Schmid, O., Yang, H., Yu, J.-Z. and Zhang, Y.-H.: Optical properties and chemical composition of the atmospheric aerosol in urban Guangzhou, China, Atmos. Environ., 42, 63356350, doi:10.1016/j.atmosenv.2008.01.030, 2008.

Andreae, T. W., Andreae, M. O., Ichoku, C., Maenhaut, W., Cafmeyer, J., Karnieli, A. and Orlovsky, L.: Light scattering by dust and anthropogenic aerosol at a remote site in the Negev desert, Israel, J. Geophys. Res.-Atmos., 107, 4008, doi:10.1029/2001JD900252, 2002.

Ångström, A.: On the atmospheric transmission of sun radiation and on dust in the air, Geogr. Ann., 11, 156-166, 1929.

Arnott, W. P., Moosmuller, H., Rogers, C. F., Jin, T. F., and Bruch, R.: Photoacoustic spectrometer for measuring light absorption by aerosol: instrument description, Atmos. Environ., 33, 28452852, 1999.

Arnott, W. P., Moosmuller, H., and Walker, J. W.: Nitrogen dioxide and kerosene-flame soot calibration of photoacoustic instruments for measurement of light absorption by aerosols, Rev. Sci. Instrum., 71, 4545-4552, 2000.

Ayers, G. P.: Comment on regression analysis of air quality data, Atmos. Environ., 35, 2423-2425, 2001.

Baumgardner, D.: Diagnosing black carbon trends in large urban areas using carbon monoxide measurements, J. Geophys. Res.Atmos., 107(D21), 8342, doi:10.1029/2001JD000626, 2002.

Baumgardner, D.: On the diurnal variability of particle properties related to light absorbing carbon in Mexico City, Atmos. Chem. Phys., 7, 2517-2526, 2007, http://www.atmos-chem-phys.net/7/2517/2007/.

Bergin, M. H., Cass, G. R., Xu, J., Fang, C., Zeng, L. M., Yu, T., Salmon, L. G., Kiang, C. S., Tang, X. Y., Zhang, Y. H., and 
Chameides, W. L.: Aerosol radiative, physical, and chemical properties in Beijing during June 1999, J. Geophys. Res.-Atmos., 106, 17 969-17 980, 2001.

Bergstrom, R. W., Pilewskie, P., Russell, P. B., Redemann, J., Bond, T. C., Quinn, P. K., and Sierau, B.: Spectral absorption properties of atmospheric aerosols, Atmos. Chem. Phys., 7, 5937-5943, 2007 , http://www.atmos-chem-phys.net/7/5937/2007/.

Bergstrom, R. W., Russell, P. B., and Hignett, P.: Wavelength dependence of the absorption of black carbon particles: Predictions and results from the TARFOX experiment and implications for the aerosol single scattering albedo, J. Atmos. Sci., 59, 567-577, 2002.

Bond, T. C.: Light absorption by carbonaceous particles: an investigative review, Aerosol Sci. Tech., 40, 27-67, 2006.

Bradsher, K.: Trucks power China's economy, at a suffocating cost. The New York Times, NY, USA, 8 December 2007.

Cao, J. J., Lee, S. C., Ho, K. F., Zhang, X. Y., Zou, S. C., Fung, K., Chow, J. C., and Watson, J. G.: Characteristics of carbonaceous aerosol in Pearl River Delta Region, China during 2001 winter period, Atmos. Environ., 37, 1451-1460, 2003.

Cao, J. J., Lee, S. C., Ho, K. F., Zou, S. C., Fung, K., Li, Y., Watson, J. G., and Chow, J. C.: Spatial and seasonal variations of atmospheric organic carbon and elemental carbon in Pearl River Delta Region, China, Atmos. Environ., 38, 4447-4456, 2004.

Carrico, C. M., Bergin, M. H., Xu, J., Baumann, K., and Maring, H.: Urban aerosol radiative properties: Measurements during the 1999 Atlanta Supersite Experiment, J. Geophys. Res.-Atmos., 108(D7), 8422, doi:10.1029/2001JD001222, 2003.

Chan, C. K. and Yao, X.: Air pollution in mega cities in China, Atmos. Environ., 42, 1-42, 2008.

Chen, D. S., Cheng, S. Y., Liu, L., Chen, T., and Guo, X. R.: An integrated MM5-CMAQ modeling approach for assessing transboundary $\mathrm{PM}_{10}$ contribution to the host city of 2008 Olympic summer games - Beijing, China, Atmos. Environ., 41, 12371250, 2007.

Chen, L. W. A., Doddridge, B. G., Dickerson, R. R., Chow, J. C., Mueller, P. K., Quinn, J., and Butler, W. A.: Seasonal variations in elemental carbon aerosol, carbon monoxide and sulfur dioxide: Implications for sources, Geophys. Res. Lett., 28, 17111714, 2001.

Cheng, Y., Lee, S. C., Ho, K. F., Wang, Y. Q., Cao, J. J., Chow, J. C., and Watson, J. G.: Black carbon measurement in a coastal area of south China, J. Geophys. Res.-Atmos., 111, D12310, doi:10.1029/2005JD006663, 2006a.

Cheng, Y. F., Eichler, H., Wiedensohler, A., Heintzenberg, J., Zhang, Y. H., Hu, M., Herrmann, H., Zeng, L. M., Liu, S., Gnauk, T., Bruggemann, E., and He, L. Y.: Mixing state of elemental carbon and non-light-absorbing aerosol components derived from in situ particle optical properties at Xinken in Pearl River Delta of China, J. Geophys. Res.-Atmos., 111, D20204, doi:10.1029/2005JD006929, 2006b.

Cheng, Y. F., Wiedensohler, A., Eichler, H., Heintzenberg, J., Tesche, M., Ansmann, A., Wendisch, M., Su, H., Althausen, D., Herrmann, H., Gnauk, T., Brüggemann, E., Hu, M., and Zhang, Y. H.: Relative humidity dependence of aerosol optical properties and direct radiative forcing in the surface boundary layer at Xinken in the Pearl River Delta of China: An observation based numerical study, Atmos. Environ., 42(25), 6373-
6397, doi:10.1016/j.atmosenv.2008.04.009, 2008a.

Cheng, Y. F., Wiedensohler, A., Eichler, H., Su, H., Gnauk, T., Brüggemann, E., Herrmann, H., Heintzenberg, J., Slanina, S., Tuch, T., Hu, M., and Zhang, Y. H.: Aerosol optical properties and related chemical apportionment at Xinken in Pearl River Delta of China, Atmos. Environ., 42(25), 6351-6372, doi:10.1016/j.atmosenv.2008.02.034, 2008b.

Derimian, Y., Karnieli, A., Kaufman, Y. J., Andreae, M. O., Andreae, T. W., Dubovik, O., Maenhut, W., and Koren, I.: The role of iron and clack carbon in aerosol light absorption, Atmos. Chem. Phys., 8, 3623-3637, 2008,

http://www.atmos-chem-phys.net/8/3623/2008/.

Draxler, R. R. and Rolph, G. D.: HYSPLIT (HYbrid Single-Partilce Lagrangian Integrated Trajectory), available at: http://www.arl. noaa.gov/ready/hysplit4.html, last access June 2008, 2008.

Eck, T. F., Holben, B. N., Reid, J. S., Dubovik, O., Smirnov, A., O'Neill, N. T., Slutsker, I., and Kinne, S.: Wavelength dependence of the optical depth of biomass burning, urban, and desert dust aerosols, J. Geophys. Res.-Atmos., 104, 31 333-31349, 1999.

Eck, T. F., Holben, B. N., Ward, D. E., Dubovik, O., Reid, J. S., Smirnov, A., Mukelabai, M. M., Hsu, N. C., O’Neill, N. T., and Slutsker, I.: Characterization of the optical properties of biomass burning aerosols in Zambia during the 1997 ZIBBEE field campaign, J. Geophys. Res.-Atmos., 106, 3425-3448, 2001.

Fialho, P., Hansen, A. D. A., and Honrath, R. E.: Absorption coefficients by aerosols in remote areas: a new approach to decouple dust and black carbon absorption coefficients using sevenwavelength Aethalometer data, J. Aerosol Sci., 36, 267-282, 2005.

Finlayson-Pitts, B. and Pitts Jr., J.: Chemistry of the Upper and Lower Atmosphere, Academic Press, New York, USA, 1999.

Fujitani, Y., Murao, N., Ohta, S., Endoch, T., and Yamagata, S.: Optical and chemical properties of marine aerosols over the central equatorial Pacific Ocean during the 2003 R/V Mirai cruise, J. Geophys. Res., 112, D11213, doi:10.1029/2006JD008354, 2007.

Garland, R. M., Ravishankara, A. R., Lovejoy, E. R., Tolbert, M. A., and Baynard, T.: Parameterization for the relative humidity dependence of light extinction: Organicammonium sulfate aerosol, J. Geophys. Res.-Atmos., 112, D19303, doi:10.1029/2006JD008179, 2007.

Gobbi, G. P., Kaufman, Y. J., Koren, I., and Eck, T. F.: Classification of aerosol properties derived from AERONET direct sun data, Atmos. Chem. Phys., 7, 453-458, 2007, http://www.atmos-chem-phys.net/7/453/2007/.

Hagler, G. S., Bergin, M. H., Salmon, L. G., Yu, J. Z., Wan, E. C. H., Zheng, M., Zeng, L. M., Kiang, C. S., Zhang, Y. H., Lau, A. K. H., and Schauer, J. J.: Source areas and chemical composition of fine particulate matter in the Pearl River Delta region of China, Atmos. Environ., 40, 3802-3815, 2006.

Hammer, Ø., Harper, D. A. T., and Ryan, P. D.: PAST: Paleontological Statistics Software Package for Education and Data Analysis, Palaeontol. Electron., 4, 1-9, 2001.

Haywood, J. M. and Shine, K. P.: The Effect of Anthropogenic Sulfate and Soot Aerosol on the Clear-Sky Planetary Radiation Budget, Geophys. Res. Lett., 22, 603-606, 1995.

Hua, W., Chan, Z. M., Jie, C. Y., Kondo, Y., Hofzumahaus, A., Takegawa, N., Lu, K. D., Miyazaki, Y., Kita, K., Zhang, Y. $\mathrm{H}$. and $\mathrm{Hu}, \mathrm{M} .:$ Atmospheric hydrogen peroxide and organiy 
hydroperoxides during PRIDE-PRD2006, China: their concentration, formation mechanism and contribution to secondary aerosol, Atmos. Chem. Phys. Discuss., 8, 10 481-10 530, 2008, http://www.atmos-chem-phys-discuss.net/8/10481/2008/.

IPCC, (2001): "Climate change 2001: the scientific basis", Intergovernmental Panel on Climate Change, http://www.grida.no/ climate/ipcc_tar/wg1/index.htm., last access August 2008.

Jennings, S. G., Spain, T. G., Doddridge, B. G., Maring, H., Kelly, B. P. and Hansen, A. D. A.: Concurrent measurements of black carbon aerosol and carbon monoxide at Mace Head, J. Geophys. Res.-Atmos., 101, 19447-19454, 1996.

Jiang, M., Marr, L. C., Dunlea, E. J., Herndon, S. C., Jayne, J. T., Kolb, C. E., Knighton, W. B., Rogers, T. M., Zavala, M., Molina, L. T., and Molina, M. J.: Vehicle fleet emissions of black carbon, polycyclic aromatic hydrocarbons, and other pollutants measured by a mobile laboratory in Mexico City, Atmos. Chem. Phys., 5, 3377-3387, 2005, http://www.atmos-chem-phys.net/5/3377/2005/.

Kaiser, D. P. and Qian, Y.: Decreasing trends in sunshine duration over China for 1954-1998: Indication of increased haze pollution?, Geophys. Res. Lett., 29(21), 2042, doi:10.1029/2002GL016057, 2002.

Keeling, R. F., Piper, S. C., and Heimann, M.: Global and hemispheric $\mathrm{CO}_{2}$ sinks deduced from changes in atmospheric $\mathrm{O}_{2}$ concentration, Nature, 381, 218-221, 1996.

Kim, K. W., He, Z. S., and Kim, Y. J.: Physicochemical characteristics and radiative properties of Asian dust particles observed at Kwangju, Korea, during the 2001 ACE-Asia intensive observation period, J. Geophys. Res.-Atmos., 109, D19S02, doi:10.1029/2003JD003693, 2004.

King, M. D. and Byrne, D. M.: Method for inferring total ozone content from spectral variation of total optical depth obtained with a solar radiometer, J. Atmos. Sci., 33, 2242-2251, 1976.

Kondo, Y., Komazaki, Y., Miyazaki, Y., Moteki, N., Takegawa, N., Kodama, D., Deguchi, S., Nogami, M., Fukuda, M., Miyakawa, T., Morino, Y., Koike, M., Sakurai, H., and Ehara, K.: Temporal variations of elemental carbon in Tokyo, J. Geophys. Res.Atmos., 111, D12205, doi:10.1029/2005JD006257, 2006.

Lawrence, M. G., Butler, T. M., Steinkamp, J., Gurjar, B. R., and Lelieveld, J.: Regional pollution potentials of megacities and other major population centers, Atmos. Chem. Phys., 7, 39693987, 2007, http://www.atmos-chem-phys.net/7/3969/2007/.

Li, C., Marufu, L. T., Dickerson, R. R., Li, Z. Q., Wen, T. X., Wang, Y. S., Wang, P. C., Chen, H. B., and Stehr, J. W.: In situ measurements of trace gases and aerosol optical properties at a rural site in northern China during East Asian Study of Tropospheric Aerosols: an international regional experiment 2005, J. Geophys. Res.-Atmos., 112, D22S04, doi:10.1029/2006JD007592, 2007.

Li, Y., Demetriadesshah, T. H., Kanemasu, E. T., Shultis, J. K., and Kirkham, M. B.: Use of 2nd Derivatives of Canopy Reflectance for Monitoring Prairie Vegetation over Different Soil Backgrounds, Remote Sens. Environ., 44, 81-87, 1993.

Lim, H. J.: Origins of primary and secondary organic aerosol in Atlanta: Results' of time-resolved measurements during the Atlanta supersite experiment, Environ. Sci. Technol., 36, 44894496, 2002.

Liu, X. G., Cheng, Y. F., Zhang, Y. H., Jung, J. S., Sugimoto, N., Chang, S. Y., Kim, Y. J., Fan, S. J., and Zeng, L. M.: Influ- ences of relative humidity and particle chemical composition on aerosol scattering properties during the 2006 PRD campaign, Atmos. Environ., 42, 1525-1536, 2008.

Malm, W. C., Day, D. E., Carrico, C., Kreidenweis, S. M., Collett, J. L., McMeeking, G., Lee, T., Carrillo, J., and Schichtel, B.: Intercomparison and closure calculations using measurements of aerosol species and optical properties during the Yosemite Aerosol Characterization Study, J. Geophys. Res.-Atmos., 110, D10302, doi:10.1029/2004JD005494, 2005.

Man, C. K. and Shih, M. Y.: Light scattering and absorption properties of aerosol particles in Hong Kong, J. Aerosol Sci., 32, 795804, 2001.

Mikhailov, E. F., Vlasenko, S. S., Podgorny, I. A., Ramanathan, V., and Corrigan, C. E.: Optical properties of soot-water drop agglomerates: An experimental study, J. Geophys. Res.-Atmos., 111, D07209, doi:10.1029/2005Jd006389, 2006.

Nakajima, T. and Higurashi, A.: A use of two-channel radiances for an aerosol characterization from space, Geophys. Res. Lett., 25, 3815-3818, 1998.

NBS: National Bureau of Statistics of the People's Republic of China, available at: www.stats.gov.cn, last access August 2008.

Nessler, R., Weingartner, E., and Baltensperger, U.: Effect of humidity on aerosol light absorption and its implications for extinction and the single scattering albedo illustrated for a site in the lower free troposphere, J. Aerosol Sci., 36, 958-972, 2005.

O’Neill, N. T., Eck, T. F., Holben, B. N., Smirnov, A., Dubovik, O., and Royer, A.: Bimodal size distribution influences on the variation of Angstrom derivatives in spectral and optical depth space, J. Geophys. Res.-Atmos., 106, 9787-9806, 2001.

Ouyang, T. P., Zhu, Z. Y. and Kuang, Y. Q.: Assessing impact of urbanization on river water quality in the Pearl River Delta Economic Zone, China, Environ. Monit. Assess., 120, 313-325, 2006.

Park, S. S.: Highly time-resolved organic and elemental carbon measurements at the Baltimore Supersite in 2002, J. Geophys. Res.-Atmos., 110, D07S06, doi:10.1029/2004JD004610, 2005.

Pöschl, U.: Atmospheric aerosols: Composition, transformation, climate and health effects, Angew. Chem.-Int. Ed., 44, 75207540, 2005.

Quinn, P. K. and Bates, T. S.: Regional aerosol properties: Comparisons of boundary layer measurements from ACE 1, ACE 2, aerosols99, INDOEX, ACE asia, TARFOX, and NEAQS, J. Geophys. Res.-Atmos., 110, D14202, doi:10.1029/2004JD004755, 2005.

Quinn, P. K., Coffman, D. J., Bates, T. S., Welton, E. J., Covert, D. S., Miller, T. L., Johnson, J. E., Maria, S., Russell, L., Arimoto, R., Carrico, C. M., Rood, M. J., and Anderson, J.: Aerosol optical properties measured on board the Ronald H. Brown during ACE-Asia as a function of aerosol chemical composition and source region, J. Geophys. Res.-Atmos., 109, D19S01, doi:10.1029/2003JD004010, 2004.

Quinn, P. K., Coffman, D. J., Kapustin, V. N., Bates, T. S., and Covert, D. S.: Aerosol optical properties in the marine boundary layer during the First Aerosol Characterization Experiment (ACE 1 ) and the underlying chemical and physical aerosol properties, J. Geophys. Res.-Atmos., 103, 16 547-16 563, 1998.

Reid, J. S.: Physical and optical properties of young smoke from individual biomass fires in Brazil, J. Geophys. Res.-Atmos., 103, 32 013-32 030, 1998. 
Reid, J. S., Koppmann, R., Eck, T. F., and Eleuterio, D. P.: A review of biomass burning emissions part II: intensive physical properties of biomass burning particles, Atmos. Chem. Phys., 5, 799825,2005 , http://www.atmos-chem-phys.net/5/799/2005/.

Saathoff, H., Naumann, K. H., Schnaiter, M., Schock, W., Mohler, O., Schurath, U., Weingartner, E., Gysel, M., and Baltensperger, $\mathrm{U}$.: Coating of soot and $\left(\mathrm{NH}_{4}\right)(2) \mathrm{SO}_{4}$ particles by ozonolysis products of alpha-pinene, J. Aerosol Sci., 34, 1297-1321, 2003.

Schmid, O., Artaxo, P., Arnott, W. P., Chand, D., Gatti, L. V., Frank, G. P., Hoffer, A., Schnaiter, M., and Andreae, M. O.: Spectral light absorption by ambient aerosols influenced by biomass burning in the Amazon Basin - 1: Comparison and field calibration of absorption measurement techniques, Atmos. Chem. Phys., 6, 3443-3462, 2006,

http://www.atmos-chem-phys.net/6/3443/2006/.

Schnaiter, M.: Measurement of wavelength-resolved light absorption by aerosols utilizing a UV-VIS extinction cell, Aerosol Sci. Tech., 39, 249-260, 2005.

Schuster, G. L., Dubovik, O., and Holben, B. N.: Angstrom exponent and bimodal aerosol size distributions, J. Geophys. Res.Atmos., 111, D07207, doi:10.1029/2005JD006328, 2006.

Seinfeld, J. and Pandis, S.: Atmospheric Chemistry and Physics: from air pollution to climate change, John Wiley and Sons, New York, USA, 1998.

Sheridan, P. J. and Ogren, J. A.: Observations of the vertical and regional variability of aerosol optical properties over central and eastern North America, J. Geophys. Res.-Atmos., 104, 16793$16805,1999$.

Streets, D. G., Bond, T. C., Carmichael, G. R., Fernandes, S. D., Fu, Q., He, D., Klimont, Z., Nelson, S. M., Tsai, N. Y., Wang, M. Q., Woo, J. H., and Yarber, K. F.: An inventory of gaseous and primary aerosol emissions in Asia in the year 2000, J. Geophys. Res.-Atmos., 108(D21), 8809, doi:10.1029/2002JD003093, 2003.

Stunder, B.: FNL Readme File, available at: http://www.arl.noaa. gov/ready-bin/fnl.pl, last access August 2008, 1997.

Takegawa, N., Miyakawa, T., Kondo, Y., Jimenez, J. L., Zhang, Q., Worsnop, D. R., and Fukuda, M.: Seasonal and diurnal variations of submicron organic aerosol in Tokyo observed using the Aerodyne aerosol mass spectrometer, J. Geophys. Res.-Atmos., 111, D11206, doi:10.1029/2005JD006515, 2006.
United Nations Organization: World Urbanization Prospects: the 2005 Revision, available at: http://www.un.org/esa/population/ publications/WUP2005/2005WUPHighlights_Final_Report.pdf, last access August 2008.

Waggoner, A. P., Weiss, R. E., Ahlquist, N. C., Covert, D. S., Will, S., and Charlson, R. J.: Optical Characteristics of Atmospheric Aerosols, Atmos. Environ., 15, 1891-1909, 1981.

Wang, W., Rood, M., Carrico, C., Covert, D., Quinn, P., and Bates, T.: Aerosol optical properties along the northeast coast of North America during the New England Air Quality StudyIntercontinental Transport and Chamiecal Transformation 2004 campaign and the influence of aerosol composition, J. Geophys. Res., 112, D10S23, doi:10.1029/2006JD007579, 2007.

Wehner, B., Birmili, W., Ditas, F., Wu, Z., Hu, M., Liu, X., Mao, J., Sugimoto, N., and Wiedensohler, A.: Relationships between submicrometer particulate air pollution and air mass history in Beijing, China, 2004-2006, Atmos. Chem. Phys. Discuss., 8, 11321-11362, 2008, http://www.atmos-chem-phys-discuss.net/8/11321/2008/.

Wei, F., Teng, E., Wu, G., Hu, W., Wilson, W. E., Chapman, R. S., Pau, J. C., and Zhang, J.: Ambient concentrations and elemental compositions of $\mathrm{PM}_{10}$ and $\mathrm{PM}_{2.5}$ in four Chinese cities, Environ. Sci. Technol., 33, 4188-4193, 1999.

Wiscombe, W. J. and Grams, G. W.: Backscattered Fraction in 2Stream Approximations, J. Atmos. Sci., 33, 2440-2451, 1976.

Wu, D., Tie, X. X., Li, C. C., Ying, Z. M., Lau, A. K. H., Huang, J., Deng, X. J., and Bi, X. Y.: An extremely low visibility event over the Guangzhou region: a case study, Atmos. Environ., 39, 6568-6577, 2005.

Xu, J., Bergin, M. H., Yu, X., Liu, G., Zhao, J., Carrico, C. M., and Baumann, K.: Measurement of aerosol chemical, physical and radiative properties in the Yangtze delta region of China, Atmos. Environ., 36, 161-173, 2002.

Zhang, Y. H., Hu, M., Zhong, L. J., Wiedensohler, A., Liu, S. C., Andreae, M. O., Wang, W., and Fan, S. J.: Regional integrated experiemnts on air quality over Pearl River Delta 2004 (PRIDE-PRD2004), Atmos. Environ., 42, 6157-6173, doi:10.1016/j.atmosenv.2008.03.0235, 2008. 